\title{
Deriving an atmospheric budget of total organic bromine using airborne in situ measurements from the western Pacific area during SHIVA
}

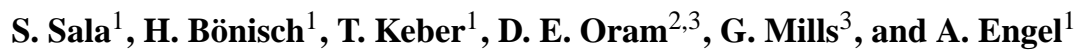 \\ ${ }^{1}$ Goethe University Frankfurt/Main, Frankfurt/Main, Germany \\ ${ }^{2}$ National Centre for Atmospheric Science, University of East Anglia, Norwich, UK \\ ${ }^{3}$ Centre for Oceanic and Atmospheric Science, University of East Anglia, Norwich, UK
}

Correspondence to: S. Sala (s.sala@iau.uni-frankfurt.de)

Received: 9 January 2014 - Published in Atmos. Chem. Phys. Discuss.: 21 February 2014

Revised: 14 May 2014 - Accepted: 15 May 2014 - Published: 4 July 2014

\begin{abstract}
During the recent SHIVA (Stratospheric Ozone: Halogen Impacts in a Varying Atmosphere) project an extensive data set of all halogen species relevant for the atmospheric budget of total organic bromine was collected in the western Pacific region using the Falcon aircraft operated by the German Aerospace agency DLR (Deutsches Zentrum für Luft- und Raumfahrt) covering a vertical range from the planetary boundary layer up to the ceiling altitude of the aircraft of $13 \mathrm{~km}$. In total, more than 700 measurements were performed with the newly developed fully automated in situ instrument GHOST-MS (Gas chromatograph for the Observation of Tracers - coupled with a Mass Spectrometer) by the Goethe University of Frankfurt (GUF) and with the onboard whole-air sampler WASP with subsequent groundbased state-of-the-art GC/MS analysis by the University of East Anglia (UEA). Both instruments yield good agreement for all major $\left(\mathrm{CHBr}_{3}\right.$ and $\left.\mathrm{CH}_{2} \mathrm{Br}_{2}\right)$ and minor $\left(\mathrm{CH}_{2} \mathrm{BrCl}\right.$, $\mathrm{CHBrCl}_{2}$ and $\mathrm{CHBr}_{2} \mathrm{Cl}$ ) VSLS (very short-lived substances), at least at the level of their $2 \sigma$ measurement uncertainties.

In contrast to the suggestion that the western Pacific could be a region of strongly increased atmospheric VSLS abundance (Pyle et al., 2011), we found only in the upper troposphere a slightly enhanced amount of total organic bromine from VSLS relative to the levels reported in Montzka and Reimann et al. (2011) for other tropical regions.

From the SHIVA observations in the upper troposphere, a budget for total organic bromine, including four halons $(\mathrm{H}-$ 1301, $\mathrm{H}-1211, \mathrm{H}-1202, \mathrm{H}-2402), \mathrm{CH}_{3} \mathrm{Br}$ and the VSLS, is derived for the level of zero radiative heating (LZRH), the
\end{abstract}

input region for the tropical tropopause layer (TTL) and thus also for the stratosphere.

With the exception of the two minor VSLS $\mathrm{CHBrCl}_{2}$ and $\mathrm{CHBr}_{2} \mathrm{Cl}$, excellent agreement with the values reported in Montzka and Reimann et al. (2011) is found, while being slightly higher than previous studies from our group based on balloon-borne measurements.

\section{Introduction}

Bromine atoms are very efficient catalysts in destroying stratospheric ozone. On average bromine atoms are more effective by a factor of 64 than chlorine atoms in destroying ozone in the altitude range from 10 to $50 \mathrm{~km}$ (Sinnhuber et al., 2009). Therefore, even small amounts of bromine play an important role in stratospheric ozone chemistry. In contrast to chlorine, the sources of bromine to the stratosphere are to a large part of natural origin (e.g. Montzka and Reimann et al., 2011). The contribution of the so-called very short-lived substances (VSLS), having atmospheric lifetimes of less than half a year, as source gases for stratospheric bromine is significant. However, source gas observations of long-lived bromine compounds (Newland et al., 2013; Fraser et al., 1999) and VSLS in the tropical tropopause region (Laube et al., 2008; Brinckmann et al., 2012; Montzka and Reimann et al., 2011) have so far not been able to explain the amount of bromine derived in the stratosphere from observations of stratospheric BrO (e.g. Dorf et al., 2006; Montzka and Reimann et al., 2011). Due to the short lifetimes and 
the high atmospheric variability, the representativeness of the available observations of VSLS source gases remains unclear, as these may vary with region and display seasonal variability.

The major bromine VSLS are dibromomethane $\left(\mathrm{CH}_{2} \mathrm{Br}_{2}\right)$ and bromoform $\left(\mathrm{CHBr}_{3}\right)$, both having mainly oceanic sources including macroalgae and phytoplankton (e.g. Carpenter et al., 2000, 2003; Baker et al., 2001), in particular in coastal regions and regions of oceanic upwelling (Quack and Wallace, 2004). In addition there are three mixed bromochlorocarbons contributing to stratospheric bromine: $\mathrm{CH}_{2} \mathrm{BrCl}, \mathrm{CHBr}_{2} \mathrm{Cl}$ and $\mathrm{CHBr}_{2} \mathrm{Cl}$. With the exception of $\mathrm{CH}_{2} \mathrm{BrCl}$ the mixing ratios of all of these bromine-carrying compounds show linear correlations in the troposphere with Pearson product-moment correlation coefficients $(R)$ mostly greater than 0.8 (Brinckmann et al., 2012). The sources of these compounds to the atmosphere are therefore expected to be very similar and mainly of marine origin. A detailed overview of the emissions of brominated halocarbons by tropical macroalgae is given in Leedham et al. (2013). Due to the short lifetimes and inhomogeneous sources, these species have a high atmospheric variability and in addition they are partly destroyed in the troposphere including during transport through the TTL into the stratosphere.

The fate of the organic and inorganic product gases from the degradation of brominated VSLS in the upper tropical troposphere and TTL is still largely unknown as so far no observations of these are available in this region of the atmosphere. To our knowledge there is only a single balloon profile showing $\mathrm{BrO}$ close to the detection limit (Dorf et al., 2006; Montzka and Reimann et al., 2011).

The contribution of product gases (so-called product gas injection) to stratospheric bromine therefore needs to be determined either from modelling studies or from observations of source gases using specific assumptions on the transport into the stratosphere and chemical reactions and washout during this transport process (e.g. Aschmann et al., 2009; Hossaini et al., 2010; Liang et al., 2010; Tegtmeier et al., 2012). In contrast to longer-lived source gases, measurements of these VSLS from the planetary boundary layer can therefore not be used to constrain the amount of halogen input into the stratosphere.

As the VSLS are largely of natural origin, the emissions of these species are expected to display significant geographical and temporal variability. They are further prone to changes due to variations in climate or due to changes in land and/or ocean use (e.g. seaweed farming). It is therefore important to understand the geographical variability and the present-day budget of these gases in the atmosphere. In the future, an increasing relative contribution to stratospheric chlorine and bromine from VSLS is expected as anthropogenic long-lived bromine (Newland et al., 2013) and chlorine (e.g. Montzka and Reimann et al., 2011) source gases decline in the atmosphere in response to the Montreal Protocol.
Historical measurements of VSLS in the tropics have been compiled in Montzka and Reimann et al. (2011). Most of the data available for the free and upper tropical troposphere are derived from measurement campaigns conducted in the eastern Pacific and the Caribbean. However the western Pacific is thought to be the most important source region for air masses to be transported from the troposphere through the TTL and into the stratosphere (e.g. Newell and Gould-Stewart, 1981; Gettelman et al., 2002; Fueglistaler et al., 2004; Aschmann et al., 2009; Fueglistaler et al., 2009). High mixing ratios of brominated VSLS have also been observed occasionally in the atmospheric boundary layer in this region (Pyle et al., 2011) and also upper tropospheric values were slightly elevated relative to other atmospheric regions (Wisher et al., 2014). Due to the low ozone values observed in the upper troposphere in this region, low $\mathrm{OH}$ values and a low oxidation capacity are expected in this region resulting in prolonged lifetimes of many trace species (Kley et al., 1996; Solomon et al., 2005; Rex et al., 2014). Hossaini et al. (2013) used their 3 -D chemical transport model to evaluate a range of different emission inventories (Warwick et al., 2006; Liang et al., 2010; Ziska et al., 2013). For this purpose the model outputs for the different emission inventories were compared to independent atmospheric observations including the SHIVA aircraft data, and revealed that significant differences in these scenarios exist for many geographical regions including the western Pacific region.

Here, we present an extensive bromocarbon data set from the SHIVA aircraft campaign in the western Pacific region in November and December 2011. Measurements were made using a novel in situ, fully automated gas chromatograph coupled with a mass spectrometer (GC / MS) in addition to a whole-air sampling system (WASP) with subsequent groundbased GC / MS analysis. The in situ instrument GHOST-MS (Gas chromatograph for the Observation of Tracers - coupled with a Mass Spectrometer) was deployed for the first time during SHIVA. The measurements were performed using the Falcon aircraft operated by the German Aerospace agency DLR (Deutsches Zentrum für Luft- und Raumfahrt). Measurement flights were performed from Miri in Northwest Borneo and sampled a wide geographical range (1$8^{\circ} \mathrm{N}, 102-122^{\circ} \mathrm{E}$ ), contrasting geophysical conditions and altitudes from the planetary boundary layer up to $13 \mathrm{~km}$.

The paper is organized as follows. First, we briefly present the SHIVA aircraft campaign in the western Pacific, the instruments used for the observations and the measurement flights performed. We then discuss the data retrieval for the in situ GC/MS instrument GHOST-MS and the whole-air sampling system WASP. Finally, we present the data, compare these to other observations, derive a bromine budget for the western Pacific and derive an estimate of the amount of bromine from VSLS reaching the stratosphere. 
Table 1. Overview of the 16 measurement flights during the SHIVA aircraft campaign. Abbreviations are as follows: PBL, planetary boundary layer; RV, research vessel; UT/LS, upper troposphere/lowermost stratosphere. The different flight regions are shown in detail in Fig. 1.

\begin{tabular}{|c|c|c|c|}
\hline Flight & $\begin{array}{l}\text { Take off and } \\
\text { landing (UT) }\end{array}$ & Mission objective & Region \\
\hline 20111116a & $\begin{array}{l}04: 13 \\
07: 28\end{array}$ & PBL sampling, deep profile & Coast between Miri and Kuching \\
\hline 20111119a & $\begin{array}{l}03: 57 \\
06: 43\end{array}$ & PBL sampling, comparison RV Sonne and local boat & $\begin{array}{l}\text { Coast between } \\
\text { Miri and Kuching, } \\
\text { Kuching Bay }\end{array}$ \\
\hline $20111119 b$ & $\begin{array}{l}08: 12 \\
10: 47\end{array}$ & Outflow sampling of deep convection & Coast north of Brunei \\
\hline 20111121a & $\begin{array}{l}06: 33 \\
10: 24\end{array}$ & Lagrangian experiment: RV Sonne-Falcon & Coast near Bintulu \\
\hline $20111122 \mathrm{a}$ & $\begin{array}{l}03: 05 \\
06: 00\end{array}$ & Lagrangian experiment: RV Sonne-Falcon & Coast near Sibu \\
\hline $20111123 a$ & $\begin{array}{l}03: 09 \\
05: 25\end{array}$ & PBL sampling & $\begin{array}{l}\text { Coast between } \\
\text { Semporna and Sandakan }\end{array}$ \\
\hline $20111126 a$ & $\begin{array}{l}04: 10 \\
06: 17\end{array}$ & Deep profile upwind Borneo & Sulu Sea \\
\hline $20111126 b$ & $\begin{array}{l}08: 53 \\
09: 43\end{array}$ & Transfer back to Miri & $\begin{array}{l}\text { Sandakan-Miri } \\
\text { middle troposphere }\end{array}$ \\
\hline $20111202 \mathrm{a}$ & $\begin{array}{l}07: 03 \\
09: 30\end{array}$ & Outflow sampling of deep convection & Southwest of Miri \\
\hline $20111207 a$ & $\begin{array}{l}03: 00 \\
05: 30\end{array}$ & PBL sampling & Semporna-Tawau \\
\hline $20111207 b$ & $\begin{array}{l}06: 23 \\
09: 17\end{array}$ & Deep vertical profile, UT/LS survey & Bay of Kuching \\
\hline $20111208 \mathrm{a}$ & $\begin{array}{l}02: 07 \\
05: 11\end{array}$ & Sampling of outflow from deep convection & $\begin{array}{l}\text { Coast Kudat- } \\
\text { Sandakan }\end{array}$ \\
\hline 20111209a & $\begin{array}{l}03: 58 \\
06: 43\end{array}$ & PBL sampling, vertical transport by shallow convection & Northeastern coast of Borneo \\
\hline $20111209 b$ & $\begin{array}{l}08: 12 \\
10: 47\end{array}$ & Sampling of outflow from deep convection & Northeastern coast of Borneo \\
\hline $20111211 \mathrm{a}$ & $\begin{array}{l}03: 00 \\
06: 15\end{array}$ & PBL and convective outflow sampling & Strait of Malacca \\
\hline $20111211 b$ & $\begin{array}{l}07: 41 \\
10: 20\end{array}$ & PBL and convective outflow sampling & Strait of Malacca \\
\hline
\end{tabular}

\section{Origin of data}

\subsection{The SHIVA campaign}

One scientific aim of SHIVA was to improve the understanding of the influence of VSLS on the stratospheric halogen budget, both in the present day and in the future under the influence of a changing climate. As part of this project a field campaign in the western Pacific was conducted in November and December 2011. One focus of the campaign was the determination of the oceanic emission strength and the atmospheric mixing ratio of long- and very short-lived brominated substances. In addition, atmospheric transport from the boundary layer to the upper troposphere as well as decay processes occurring during this transport was investigated. The field campaign combined a variety of ground, air, ship and satellite-based measurements. In this paper we focus on the measurements carried out with the German research aircraft Falcon, also using some supplemental information from measurements onboard the research vessel (RV) Sonne.

The aircraft was based in Miri, Borneo (Malaysia). Between 16 November and 11 December, a total of 16 measurement flights were carried out to determine atmospheric mixing ratios of various trace gases and to study the atmospheric transport processes in this tropical region. An overview of the different flight regions and mission objectives is given in Table 1. The different flight tracks of the Falcon are shown in Fig. 1. Except for the first flight on 16 November, the instrument GHOST-MS performed very well during the campaign and obtained more than 500 measurements of ambient air in an altitude range from the ground up to $13 \mathrm{~km}$.

In addition to the in situ measurements of halogenated hydrocarbons by the GHOST-MS instrument by the Goethe University Frankfurt (GUF), the University of East Anglia 


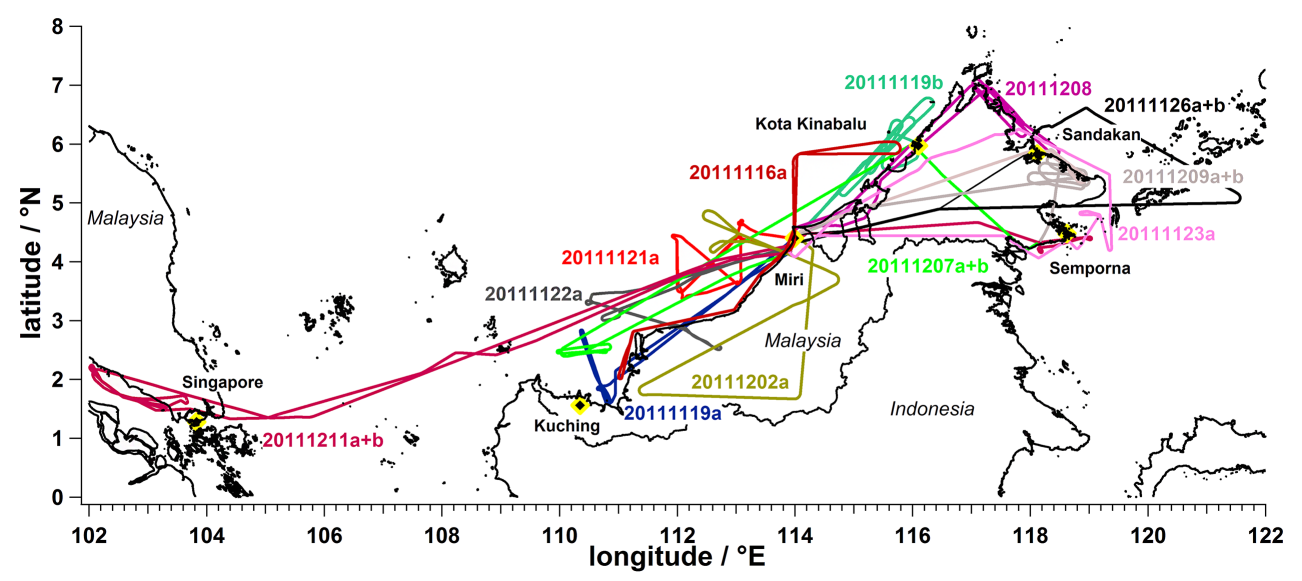

Figure 1. Overview over the different flight tracks of the Falcon during SHIVA. The colour coding indicate the different flights and the corresponding numbering is the date of the flight in the format year (YYYY), month (MM), day (DD) and a letter, whether it is the first (a) or the second (b) flight of a day.

(UEA) also investigated the mixing ratio of these species. For this a combination of the WASP instrument (Whole Air Sample Pack) with a ground-based GC/MS system was used. Overall, 215 samples covering an altitude range from the ground up to $4 \mathrm{~km}$ were analysed during the campaign.

\subsection{Instrumental setup}

\subsubsection{Gas chromatograph for observation of tracers - coupled with a mass spectrometer (GHOST-MS)}

GC / MS is a very versatile technique, widely used in atmospheric sciences for the measurements of halogenated compounds in the troposphere and stratosphere (e.g. Oram et al., 1995; Montzka et al., 1996; Schauffler et al., 2003; Laube et al., 2008; Miller et al., 2008). To the best of our knowledge only one in situ GC / MS system for airborne application has been described in the literature (Apel et al., 2003). There are very specific requirements and limitations for the operation of such an instrument onboard an aircraft. These include the speed of the chromatography, the dimensions, weight and power consumption of the instrument and the automation of the necessary pre-concentration of ambient air samples.

The principle of the analysis is as follows: ambient air is drawn with a two-stage setup of three KNF N 86 KNDCB diaphragm pumps (two in parallel and one in serial) from outside the aircraft, compressed and passed through a chemical drying agent (magnesium perchlorate) in order to remove water vapour without affecting the analytes. Afterwards the air flows through a cooled sample loop at $-80^{\circ} \mathrm{C}$, filled with an adsorption material (HayeSep D), in order to trap all condensable trace gases. After a sufficient amount of air $(150 \mathrm{ml})$ has passed through the sample loop, the loop is flash heated to $250^{\circ} \mathrm{C}$ and the condensed species are desorbed with a carrier gas on to the separation columns. After the chromatographic separation of the different species on the MXT-1 pre- column (7.5 m) and the GS-GasPro main column (22.5 m), the trace species are quantified using a mass spectrometer. To achieve a good temporal resolution, the pre-concentration on the sample loop and the chromatographic separation have to be optimized for speed.

This optimization is realized by several novel approaches during the development of the instrument. To avoid the use of liquid nitrogen or other cryogenics, which would have made the operation of the instrument onboard an aircraft much more complicated, we implemented a free piston Stirling cooler for the cooling of the sample loop. This is a very compact $(15 \times 15 \times 30 \mathrm{~cm})$, lightweight $(3 \mathrm{~kg})$ and efficient cooler (TD08, Twinbird Co.), which provides cooling temperatures down to $-100^{\circ} \mathrm{C}$ with an electrical power consumption of only $80 \mathrm{~W}$. To our knowledge, Stirling coolers have never been operated before onboard an aircraft in order to be used as cooling agents for sample loops. To achieve fast heating and cooling rates of the separation column, we used an LTM module ("Lightweight Thermal Mass Module", Agilent Technologies), which allows heating rates of well over $100 \mathrm{~K}$ per minute. This is also novel in airborne gas chromatography for the analysis of halogenated hydrocarbons.

The mass spectrometer (Agilent MSD 5975) was operated in negative ion chemical ionization (NICI) mode (e.g. Worton et al., 2008) and we were able to quantify 16 chlorinated, 10 brominated and one iodinated halocarbon in a sample of ambient air within a sample cycle of 4.3 minutes, including a chromatographic runtime of $2.9 \mathrm{~min}$. In this work only the brominated substances will be discussed. A chromatogram of the 10 identified brominated substances is shown in Fig. 2.

In addition to the time resolution, good detection limits, reproducibility and accuracy are necessary in order to resolve the atmospheric variability of the target compounds. The detection limit is calculated via the signal-to-noise ratio for each substance separately. The operation of the mass 


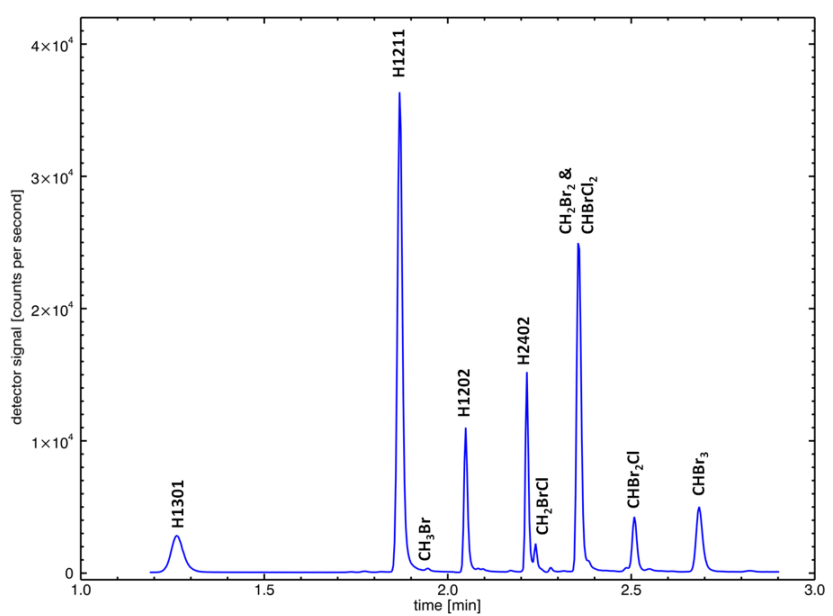

Figure 2. NICI chromatogram $(\mathrm{m} / \mathrm{z}, 79)$ from GHOST-MS instrument.

spectrometer in NICI mode enables the achievement of very low detection limits down to $1 \mathrm{ppq}$ in a $150 \mathrm{ml}$ sample of air. The precision was determined by repeat measurements of a single calibration gas over a period of several hours. Applying no correction for temporal drifts, the standard deviation of those measurements is a conservative measure for the precision of the instrument. Most of the species are reported relative to the NOAA-ESRL calibration scales (e.g. Hall et al., 2014). For the two halons H-2402 and H-1202 the calibrations are based on intercalibration experiments with the University of East Anglia (UEA). For the short-lived mixed bromochlorocarbons the data are based on a NOAA preliminary scale, transferred from UEA measurements during the measurement campaign in Borneo. The scale origin for the different substances is given in Table 2 together with the reproducibility and detection limits achieved with GHOSTMS. Note that the accuracy for the calibration gas given in Table 2 is a measure of the precision with which our calibration gases can be linked to the absolute calibration scales of NOAA and UEA.

Data processing, e.g. the integration of the signal peaks for the determination of area and height of a peak, was performed with self-written software called IAU_Chrom. The advantage of this software compared to commercially available chromatography software is the sophisticated peakfitting algorithm which fits a probability distribution (Gaussian or Gumbel function) to a peak in the predefined peak window. This is a very stable and reproducible method, especially for signal peaks with small signal-to-noise ratios or overlapping peaks.

\subsubsection{Whole Air Sample Pack (WASP)}

The WASP consisted of 30 pyrex tubes $(5 \mathrm{~cm}$ diameter, $35 \mathrm{~cm}$ long, approximately $700 \mathrm{ml}$ ) with $6 \mathrm{~mm}$ inlet and outlet tubes. The tubes were connected via PFA unions and tub- ing to two $1 / 8^{\prime \prime}$ (approx. $3.2 \mathrm{~mm}$ ) Valco STF 16-way flowthrough valves.

Inlet air was compressed with a KNF AN18 series diaphragm pump with a PTFE diaphragm and a needle valve on the WASP vent was used to regulate the fill pressure. The final fill pressure was typically $40 \mathrm{psi}$ (approx. $2800 \mathrm{hPa}$ ), although this was reduced at high altitudes due to the limitation of the pump. The sample tube was continually being flushed at elevated pressure until it was isolated by moving the Valco valve to a new position when a new sample flask was exposed and flushed. The flow rate of the flushing air was altitude dependent and so the averaging time for the flask sample ranged from $<20$ seconds at sea level up to $180 \mathrm{~s}$ at $4 \mathrm{~km}$.

Between flights the WASPs were cleaned by a series of evacuation/fill/flush cycles (using zero-grade nitrogen) and left at atmospheric pressure. Occasional blanks were performed on random sample flasks after cleaning with no problems found.

Samples were analysed on a Dual-MS GC/MS system. Analytes were separated with a temperature-programmed $105 \mathrm{~m}$ RTX-502.2 column $(0.32 \mathrm{~mm}$ id, $1 \mu \mathrm{m}$ film $)$ at constant flow, which allowed the separation of all five bromomethanes. The column effluent was split using a silcotreated Valco $1 / 32^{\prime \prime}$ (approx. $0.8 \mathrm{~mm}$ ) Y-connector in a 50 : 50 ratio into two Agilent 5973N mass spectrometers, one in electron ionization (EI) mode and one in NICI mode. Bromomethanes, other halocarbons and alkyl nitrates were measured on the negative ion channel, whilst a limited range of hydrocarbons and a range of additional halocarbons were measured on the EI channel. Carbon tetrachloride, bromoform and CFC-113 were analysed on both channels, and no significant differences in measured mole fractions were observed between the two channels.

$1200 \mathrm{ml}$ samples, dried with a $72^{\prime \prime}$ counter-flow nafion dryer, were pre-concentrated prior to injection onto the GC column with a Markes Unity thermal desorption system using a carbographB/carboxen 1003 sample trap held at $-10^{\circ} \mathrm{C}$. Injection from the trap was performed by heating the trap to $250^{\circ} \mathrm{C}$ for $15 \mathrm{~min}$. Working standards were analysed after every five samples, and a helium blank run once per day. Analytical precision, determined from seven consecutive measurements of the standard, was typically $3 \%(1 \sigma)$ for the bromomethanes and organic nitrates, and around $10 \%$ $(1 \sigma)$ for hydrocarbons. Limits of detection (based on analytical precision and blanks) varied between compounds, but for bromomethanes, most halocarbons and organic nitrates they were typically $<0.01 \mathrm{ppt}$.

Full details of the use of the Markes Unity system coupled to negative ion GC / MS can be found in Worton et al. (2008).

\subsection{Data correction}

The chromatographic system of the GHOST-MS cannot resolve the two substances $\mathrm{CH}_{2} \mathrm{Br}_{2}$ and $\mathrm{CHBrCl}_{2}$ within a regular chromatographic run as used on the aircraft, as these 
Table 2. Overview of the detection limits and measurement precision of the GHOST-MS and the origin and accuracy of the calibration scales used for the various brominated substances.

\begin{tabular}{lcccl}
\hline Substance & $\begin{array}{c}\text { Detection } \\
\text { limit [ppq] }\end{array}$ & $\begin{array}{c}\text { Average precision } \\
\text { of measurements }\end{array}$ & $\begin{array}{c}\text { Accuracy of } \\
\text { calibration gas }\end{array}$ & $\begin{array}{l}\text { Calibration } \\
\text { scale origin }\end{array}$ \\
\hline $\mathrm{H}-1301$ & 12 & $4.6 \%$ & $6.2 \%$ & NOAA, 2006 \\
$\mathrm{H}-1211$ & 1 & $2.1 \%$ & $2.2 \%$ & NOAA, 2006 \\
$\mathrm{CH} 3 \mathrm{Br}$ & 294 & $9.0 \%$ & $7.8 \%$ & NOAA, 2003 \\
$\mathrm{H}-1202$ & 1 & $5.1 \%$ & $8.6 \%$ & UEA, 2009 \\
$\mathrm{H}-2402$ & 1 & $2.4 \%$ & $4.0 \%$ & UEA, 2009 \\
$\mathrm{CH}_{2} \mathrm{BrCl}$ & 6 & $9.8 \%$ & $15.0 \%$ & NOAA, prel. \\
$\mathrm{CH}_{2} \mathrm{Br}_{2}$ & 1 & $3.4 \%$ & $10.8 \%$ & NOAA, 2004 \\
$\mathrm{CHBrCl}_{2}$ & 1 & $3.4 \%$ & $14.0 \%$ & NOAA, prel. \\
$\mathrm{CHBr}_{2} \mathrm{Cl}$ & 1 & $4.3 \%$ & $9.7 \%$ & NOAA, prel. \\
$\mathrm{CHBr}_{3}$ & 3 & $5.7 \%$ & $17.7 \%$ & NOAA, 2003 \\
\hline
\end{tabular}

substances co-elute on the separation column due to their very similar boiling point. For further data analysis, e.g. for the calculation of the budget of total organic bromine, it is necessary to know the fraction each of the two species contributes to the total peak area. While this can be done easily for the calibration gas using a slower temperature programming in the laboratory and thus separating the two peaks, it is not possible for ambient air measurements due to the limited amount of time available for the separation. The fractions of the peak area determined by this experiment for our calibration gas are $\mathrm{C}_{\mathrm{CH}_{2} \mathrm{Br}_{2}=0.6494 \pm 0.0097}$ and $\mathrm{C}_{\mathrm{CHBrCl}_{2}}=0.3506 \pm 0.0097$. The corresponding mixing ratio in the calibration gas for these peak fractions are $(3.25 \pm 0.11) \mathrm{ppt}$ for $\mathrm{CH}_{2} \mathrm{Br}_{2}$ and $(2.08 \pm 0.07) \mathrm{ppt}$ for $\mathrm{CHBrCl}_{2}$.

For the separation of the contribution of both substances to ambient air observations, we assume that a linear relationship exists between the mixing ratios of $\mathrm{CH}_{2} \mathrm{Br}_{2}$ and $\mathrm{CHBrCl}_{2}$ as described, for example, in Yokouchi et al. (2005) and Brinckmann et al. (2012). The relationship used for the SHIVA observations is based on the simultaneous WASP measurements performed by UEA. From these measurements, the linear relation between the mixing ratio of $\mathrm{CH}_{2} \mathrm{Br}_{2}$ and $\mathrm{CHBrCl}_{2}$ has been determined as (all units in ppt)

$\left[\mathrm{CHBrCl}_{2}\right]=0.3239 \cdot\left[\mathrm{CH}_{2} \mathrm{Br}_{2}\right]-0.0498$.

Assuming such a linear relationship between the mixing ratios of these two species and taking into account the relative sensitivity of the system to both compounds, which is known from laboratory measurements, the contribution to the peak area can be separated and both species can be quantified, as explained in detail in Sala (2014).

In addition to the separation of the double peak from $\mathrm{CH}_{2} \mathrm{Br}_{2}$ and $\mathrm{CHBrCl}_{2}$ the GHOST-MS as operated during SHIVA displays a memory effect, i.e. the preceding sample is not entirely flushed from the system and the instrument thus has a "memory". Only the substances $\mathrm{CH}_{2} \mathrm{Br}_{2}$, $\mathrm{CHBrCl}_{2}, \mathrm{CHBr}_{2} \mathrm{Cl}$ and $\mathrm{CHBr}_{3}$ are affected by this memory effect, the strength of which increases with increasing boiling point of the substance. The memory effect was quantified using laboratory measurements and the data were corrected accordingly. Finally, it was noted that due to a late eluting peak from the calibration gas, the sensitivity of the system was somewhat reduced immediately after the calibration gas measurements. This too was quantified by laboratory measurements and the results were corrected accordingly. The quantification is based on the difference in concentration to the previous measurement. The entire procedure for the corrections is described in detail in Sala (2014). The maximum correction which was necessary was up to $65 \%$ for some $\mathrm{CHBr}_{3}$ data points, while typically the correction was less than $10 \%$.

\subsection{Data origin and definition of altitude intervals}

For the interpretation of the measurements it is convenient to group the data into different altitude intervals and to consider these intervals separately. In this work, we focus on measurements near the source regions of VSLS - the boundary layer - as well as measurements in the upper troposphere. For the comparison with other data sets, it is also important to know the geographical origin of the data.

The data given in Montzka and Reimann et al. (2011) for the upper tropical troposphere cover an altitude range of 10 to $12 \mathrm{~km}$ (Table 1-7 in Montzka and Reimann et al., 2011) and originate from a variety of measurement campaigns which are listed in detail in Montzka and Reimann et al. (2011). The measurements of the upper troposphere during SHIVA cover an altitude range from $10 \mathrm{~km}$ to the maximum cruise altitude of the Falcon aircraft of approximately $13 \mathrm{~km}$.

The altitude range of 2 to $10 \mathrm{~km}$ covers the so-called free troposphere. This interval is used for the data reported in Montzka and Reimann et al. (2011) as well as for the SHIVA data.

The data for the marine boundary layer used in Montzka and Reimann et al. (2011) are adapted from Law and Sturges 
et al. (2007), which include all data below $1 \mathrm{~km}$. These data originate from a variety of measurement campaigns with samples taken over the entire Pacific, as well as the Atlantic and the Indian Ocean (see Law and Sturges et al. (2007) for details).

The inhomogeneous spatial sources and the variety of analytical techniques and calibrations scales contributing to the data in Montzka and Reimann et al. (2011) have to be taken into account when comparing those data with the measurements presented here. See e.g. Hall et al. (2014) for an intercomparison of different halocarbon measurement scales.

To determine the thickness of the boundary layer during SHIVA, the profiles of potential temperature, relative humidity and wind speed as well as the bulk Richardson number are used to calculate an average value as described in detail in Fuhlbrügge et al. (2012). At the transition between boundary layer and free troposphere, potential temperature increases with altitude, whereas relative humidity and wind speed mostly decrease (see e.g. the summary in Seibert et al., 2000). The three meteorological parameters are obtained from the basic instrumentation of the Falcon as well as from frequent radiosonde launches from the RV Sonne. The data from the Falcon result in an average boundary layer height of $450 \mathrm{~m}$, which is a rough estimate for the whole flight track, because the transition between the boundary layer and the free troposphere is only determined during takeoff and landing, when passing through the boundary layer. The radiosonde launches onboard the RV Sonne give information about the top of the boundary layer, which is somewhat away in space and time from the different flight tracks. The average value of $300-500 \mathrm{~m}$ from these radiosonde releases (S. Fuhlbrügge, personal communication, 2013) is in a good agreement with the altitude of $450 \mathrm{~m}$ calculated from the $\mathrm{Fal}$ con measurements (S. Fuhlbrügge, personal communication, 2013).

For the interpretation of the results we distinguish between different variables. The mean value in a given altitude interval is the arithmetic mean of all data points in that interval. The corresponding absolute standard deviation, or scatter, is determined by two factors: the measurement precision of the instrument and the atmospheric variability. These two variables are statistically not linked with each other and can therefore be combined via Gaussian error propagation:

scatter $=\sqrt{\text { precision }^{2}+\text { variability }^{2}}$

and therefore

variability $=\sqrt{\text { scatter }^{2}-\text { precision }^{2}}$.

For further considerations, the atmospheric variability is used as specified by the calculated value given in Eq. (3). The measurement precision of the instrument is taken from Table 2.

\section{Results}

\subsection{Altitude profiles of VSLS}

In this section, we present the altitude profiles of the five VSLS measured by the GHOST-MS and WASP instruments. In order to derive the total organic bromine budget, we further take into account the longer-lived bromine species, i.e. halons and $\mathrm{CH}_{3} \mathrm{Br}$ measured by the GHOST-MS instrument. The mean mixing ratio as well as the atmospheric variability in the different altitude intervals defined in Sect. 2.4 will be discussed. We consider the results from measurements in the planetary boundary layer (PBL, $0-450 \mathrm{~m}$ ), in the free troposphere (FT, 2-10 km) and in the upper troposphere (UT, 10$13 \mathrm{~km})$. The data from the UEA instrument only cover the range up to $\sim 4 \mathrm{~km}$ due to a problem with the WASP pumping system at altitudes higher than this.

The results for the major and minor VSLS derived from both instruments are summarized in Table 4. For the WASP instrument the vertical extension of the data is limited and therefore mean values, scatter and variability could only be calculated for the PBL.

Given the measurement uncertainties of both instruments, the agreement between WASP and GHOST data is within the expected range for all species. On average the values for $\mathrm{CH}_{2} \mathrm{Br}_{2}$ observed by GHOST-MS are slightly larger, while WASP $\mathrm{CHBr}_{3}$ data are higher than the GHOST measurements. The difference of about $20 \%$ for $\mathrm{CHBr}_{3}$ between GHOST and WASP is just within the range of the overall measurement uncertainty of both instruments (shown in Tables 2 and 3). For the mixed bromochlorocarbons overall reasonable agreement is observed. The differences between the two data sets are lower than $15 \%$ for all substances and within their measurement uncertainties. One can argue that the observed differences are partly caused by the high spatial and temporal variability coupled with the fact that the instruments did not measure (GHOST) or sample (WASP) exactly at the same time. A more detailed analysis of vertical distribution is given in the following sections.

\subsection{Major VSLS: $\mathrm{CH}_{2} \mathrm{Br}_{2}$ and $\mathrm{CHBr}_{3}$}

The mean mixing ratio of $\mathrm{CH}_{2} \mathrm{Br}_{2}$ in the PBL was $1.19 \mathrm{ppt}$ for the GHOST and $1.15 \mathrm{ppt}$ for the WASP data with a moderate atmospheric variability of $\pm 17 \%$ and $11 \%$ respectively (see Table 4). It is obvious from Fig. 3 that the $\mathrm{CH}_{2} \mathrm{Br}_{2}$ mean values as well as the variability (shown for better visualization only as the $95 \%$ percentiles for the WASP data) derived from UEA and GUF show an excellent agreement over the whole overlapping range of both instruments from 0 to $4 \mathrm{~km}$. Within the UT, the mean mixing ratio is $0.90 \mathrm{ppt}$ with an atmospheric variability of $\pm 13 \%$. The decay between PBL and UT is $24 \%$ - only for the GHOST data. For reasons of consistency, in the following sections, the comparisons 
Table 3. Overview of the detection limits and measurement precision of the WASP and the origin and accuracy of the calibration scales used for the various brominated substances. The accuracies are updated from Wisher et al. (2013).

\begin{tabular}{lllll}
\hline substance & $\begin{array}{l}\text { detection } \\
\text { limit [ppq] }\end{array}$ & $\begin{array}{l}\text { average precision } \\
\text { of measurements }\end{array}$ & $\begin{array}{l}\text { accuracy of } \\
\text { calibration gas }\end{array}$ & $\begin{array}{l}\text { calibration } \\
\text { scale origin }\end{array}$ \\
\hline $\mathrm{CH}_{2} \mathrm{BrCl}$ & 5 & $6 \%$ & $9 \%$ & NOAA, prel. \\
$\mathrm{CH}_{2} \mathrm{Br}_{2}$ & 1 & $3 \%$ & $7.8 \%$ & NOAA, 2004 \\
$\mathrm{CHBrCl}_{2}$ & 0.8 & $3 \%$ & $9.9 \%$ & NOAA, prel. \\
$\mathrm{CHBr}_{2} \mathrm{Cl}$ & 1 & $3 \%$ & $6.7 \%$ & NOAA, prel. \\
$\mathrm{CHBr}_{3}$ & 1 & $3 \%$ & $6 \%$ & NOAA, 2003 \\
\hline
\end{tabular}

Table 4. Overview of the averaged mixing ratio of the VSLS in the upper and free troposphere and the planetary boundary layer. The scatter is the absolute standard deviation of all measurements for the given mean value. The (atmospheric) variability is calculated as given in Eq. (2). The lifetime is given for the free troposphere (Montzka and Reimann et al., 2011). For $\mathrm{CH}_{2} \mathrm{BrCl}$, the data of flight $20111119 \mathrm{a}$ is not included in the calculation for the mean value in all three altitude ranges, as the mixing ratios during that flight are much higher (factor 2.5) than during the rest of the campaign (see also Fig. 5). Therefore we state that these high values are not representative for the mixing ratio of $\mathrm{CH}_{2} \mathrm{BrCl}$ during the campaign. For the calculation of the mean value of $\mathrm{CH}_{2} \mathrm{Br}_{2}$ and $\mathrm{CHBrCl}_{2}$ in the free troposphere, flight $20111119 \mathrm{a}$ is also not included for the same reasons (see Figs. 3 and 6).

\begin{tabular}{|c|c|c|c|c|c|c|c|c|c|}
\hline \multirow[t]{3}{*}{ Substance } & \multirow{3}{*}{$\begin{array}{l}\text { Lifetime } \\
\text { [days] }\end{array}$} & \multicolumn{2}{|c|}{ Upper troposphere } & \multicolumn{2}{|c|}{ Free troposphere } & \multicolumn{4}{|c|}{ Planetary boundary layer } \\
\hline & & \multicolumn{4}{|c|}{ GHOST } & \multicolumn{2}{|c|}{ GHOST } & \multicolumn{2}{|c|}{ WASP } \\
\hline & & $\begin{array}{l}\text { Mean } \\
\pm \text { scatter } \\
{[\mathrm{ppt}]}\end{array}$ & variability & $\begin{array}{l}\text { Mean } \\
\pm \text { scatter } \\
{[\mathrm{ppt}]}\end{array}$ & variability & $\begin{array}{l}\text { Mean } \\
\pm \text { scatter } \\
{[\mathrm{ppt}]}\end{array}$ & variability & $\begin{array}{l}\text { Mean } \\
\pm \text { scatter } \\
{[\mathrm{ppt}]}\end{array}$ & variability \\
\hline $\mathrm{CH}_{2} \mathrm{BrCl}$ & 137 & $\begin{array}{l}0.09 \\
\pm 0.02\end{array}$ & $\pm 15 \%$ & $\begin{array}{l}0.09 \\
\pm 0.02\end{array}$ & $\pm 8 \%$ & $\begin{array}{l}0.11 \\
\pm 0.02\end{array}$ & $\pm 21 \%$ & $\begin{array}{l}0.15 \\
\pm 0.05\end{array}$ & $\pm 33 \%$ \\
\hline $\mathrm{CH}_{2} \mathrm{Br}_{2}$ & 123 & $\begin{array}{l}0.90 \\
\pm 0.12\end{array}$ & $\pm 13 \%$ & $\begin{array}{l}0.88 \\
\pm 0.08\end{array}$ & $\pm 8 \%$ & $\begin{array}{l}1.19 \\
\pm 0.21\end{array}$ & $\pm 17 \%$ & $\begin{array}{l}1.15 \\
\pm 0.14\end{array}$ & $\pm 11 \%$ \\
\hline $\mathrm{CHBrCl}_{2}$ & 78 & $\begin{array}{l}0.25 \\
\pm 0.04\end{array}$ & $\pm 16 \%$ & $\begin{array}{l}0.24 \\
\pm 0.03\end{array}$ & $\pm 12 \%$ & $\begin{array}{l}0.34 \\
\pm 0.07\end{array}$ & $\pm 20 \%$ & $\begin{array}{l}0.33 \\
\pm 0.07\end{array}$ & $\pm 21 \%$ \\
\hline $\mathrm{CHBr}_{2} \mathrm{Cl}$ & 59 & $\begin{array}{l}0.19 \\
\pm 0.04\end{array}$ & $\pm 21 \%$ & $\begin{array}{l}0.18 \\
\pm 0.06\end{array}$ & $\pm 33 \%$ & $\begin{array}{l}0.32 \\
\pm 0.11\end{array}$ & $\pm 34 \%$ & $\begin{array}{l}0.33 \\
\pm 0.09\end{array}$ & $\pm 27 \%$ \\
\hline $\mathrm{CHBr}_{3}$ & 24 & $\begin{array}{l}0.61 \\
\pm 0.20\end{array}$ & $\pm 33 \%$ & $\begin{array}{l}0.56 \\
\pm 0.17\end{array}$ & $\pm 28 \%$ & $\begin{array}{l}1.43 \\
\pm 0.53\end{array}$ & $\pm 37 \%$ & $\begin{array}{l}1.90 \\
\pm 0.55\end{array}$ & $\pm 28 \%$ \\
\hline
\end{tabular}

between PBL, FT and UT mixing ratios will be done using the GHOST data set only.

With a typical free tropospheric lifetime of 123 days (Montzka and Reimann et al., 2011), $\mathrm{CH}_{2} \mathrm{Br}_{2}$ is one of the longer-lived VSLS and would therefore be expected to have a relatively homogeneous distribution above the PBL. Within the FT, the mean mixing ratio as well as the atmospheric variability do indeed have the lowest values of all VSLS with a mean mixing ratio of $0.88 \mathrm{ppt}$ and a variability of $\pm 8 \%$. One particular flight (20111119a, blue data points in Fig. 3) showed exceptionally high mixing ratios in the FT. For this reason the $\mathrm{CH}_{2} \mathrm{Br}_{2}$ (as well as for $\mathrm{CH}_{2} \mathrm{BrCl}$ and $\mathrm{CHBrCl}_{2}$ ) mixing ratios from this flight have been excluded from the calculation of the mean values shown in Table 4 .

A possible explanation for the lower mixing ratios and lower atmospheric variability in the FT compared to the UT is that the FT is less affected by direct convective outflow than the UT. Deep convection in the tropics can transport air masses with high mixing ratios from the lowest atmospheric layers to the upper layers of the troposphere within a relatively short timescale. The region of main convective outflow is located at altitudes between about 10 and $13 \mathrm{~km}$ (see e.g. the discussion in Gettelman and Forster, 2002).

Two flights performed towards the end of the campaign (20111211a and b) probed over a long flight distance the outflow from several large convective cells at an altitude of approximately $11 \mathrm{~km}$. Both of these flights show a slightly enhanced mean mixing ratio in the altitude interval between 10 and $11 \mathrm{~km}$ as indicated by the olive green line in Fig. 3. The altitude profile can also provide information on the level of entrainment, which describes the part of the atmosphere in which air is mixed into the convective cells. The mixing ratios measured in the FT between $2 \mathrm{~km}$ and $10 \mathrm{~km}$ are, except for flight 20111119a, lower than the highest mixing 


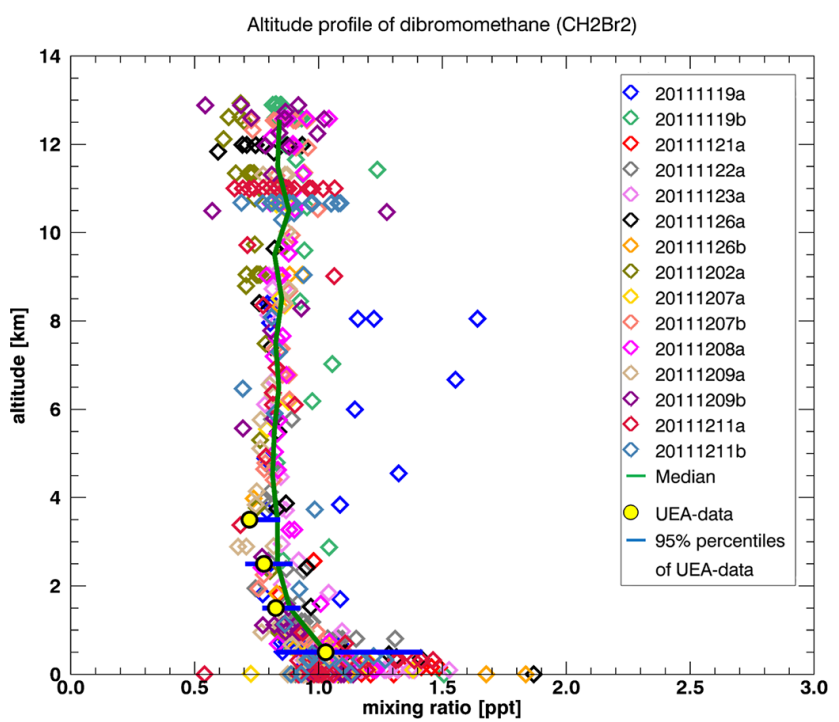

Figure 3. Vertical profile of $\mathrm{CH}_{2} \mathrm{Br}_{2}$. The colour coding indicates the different flights and the corresponding numbering is the date of the flight in the format year (YYYY), month (MM), day (DD) and a letter, whether it is the first (a) or the second (b) flight of a day. The green line marks the median of the GHOST-MS data binned in $1 \mathrm{~km}$ altitude intervals. The yellow filled circles are the median of the WASP data for the same intervals and the blue horizontal bars show the related $95 \%$ percentiles. For better visualization, no error bars for the individual points of the GHOST-MS measurements are shown. The measurement uncertainty for the particular substance is listed in Table 2.

ratios observed in the UT. This suggests that the entrainment of air masses into convective cells occurs mainly below $2 \mathrm{~km}$, where higher mixing ratios can be found. This will be discussed in more detail with respect to the observations of $\mathrm{CHBr}_{3}$.

With a free tropospheric lifetime of about 24 days (Montzka and Reimann et al., 2011), $\mathrm{CHBr}_{3}$ has the shortest atmospheric lifetime of all brominated VSLS. The altitude profile observed during SHIVA is shown in Fig. 4 . $\mathrm{CHBr}_{3}$ features larger variations than $\mathrm{CH}_{2} \mathrm{Br}_{2}$ at all altitude intervals. The mean mixing ratio in the PBL is $1.43 \mathrm{ppt}$ for the GHOST and $1.9 \mathrm{ppt}$ for the WASP data set with corresponding atmospheric variability of $\pm 37 \%$ and $\pm 28 \%$. As discussed above, the mean values in the PBL are just within the range of the uncertainties. Part of the difference could also be explained by the fact that both instruments did not always sample exactly the same air. In the lower FT, where WASP data are still available, the median and the variability for both instruments agree quite well inside the uncertainties. The highest mixing ratios of $\mathrm{CHBr}_{3}$ were found to be $3.42 \mathrm{ppt}$ (measured by GHOST-MS, near Miri) and $3.78 \mathrm{ppt}$ (measured by WASP, Strait of Malacca) respectively. In the FT the mean mixing ratio decreases to $0.56 \mathrm{ppt}$ and at the same time the atmospheric variability decreases to $\pm 28 \%$, much less pronounced than in the PBL. The altitude pro-

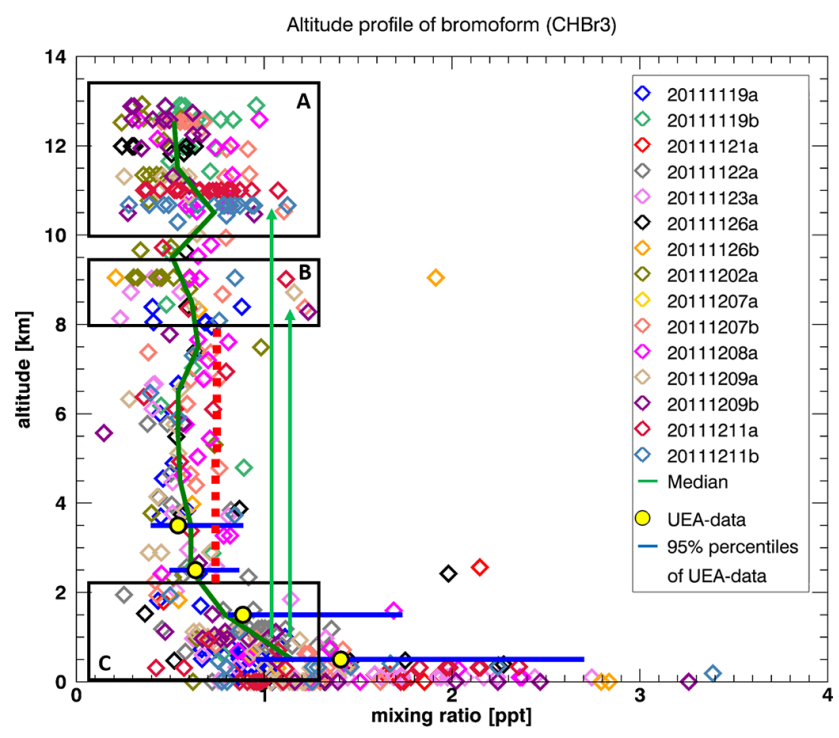

Figure 4. As Fig. 3, for $\mathrm{CHBr}_{3}$. Boxes A and $\mathrm{B}$ show regions in the upper troposphere $(10-13 \mathrm{~km}$ and $8-9.5 \mathrm{~km})$, where during some flights higher mixing ratios than in the free troposphere $(2-8 \mathrm{~km})$ occur. The red dotted line shows the mean value of $\mathrm{CHBr} 3$ plus 1 $\sigma$ atmospheric variability in the free troposphere (see also Table 4). The green arrows show possible transport pathways for air masses with higher mixing ratios from the planetary boundary layer (box C) into the upper regions of the atmosphere (boxes B and C).

file of $\mathrm{CHBr}_{3}$ shows a much stronger vertical gradient than the profile of the longer-lived substance $\mathrm{CH}_{2} \mathrm{Br}_{2}$. The decrease in the mean mixing ratio between $\mathrm{PBL}$ and FT for $\mathrm{CHBr}_{3}$ is $61 \%$ and thus, as expected, significantly higher than for $\mathrm{CH}_{2} \mathrm{Br}_{2}$, for which the mean mixing ratio decreases by only $26 \%$. At altitudes between $10 \mathrm{~km}$ and $13 \mathrm{~km}$ (Box A in Fig. 4) both, the mean mixing ratio $(0.61 \mathrm{ppt})$ and the atmospheric variability $( \pm 33 \%)$, increase again in the UT compared to the FT. The decay in mixing ratio between PBL and UT is $57 \%$ for $\mathrm{CHBr}_{3}$ in contrast to only $24 \%$ observed for $\mathrm{CH}_{2} \mathrm{Br}_{2}$.

In contrast to the profile of $\mathrm{CH}_{2} \mathrm{Br}_{2}$, the profile of $\mathrm{CHBr}_{3}$ shows a region in the upper part of the FT with enhanced mixing ratios compared to the lower part of the FT. This region is marked with Box B in Fig. 4 and is located at an altitude of $8-9.5 \mathrm{~km}$. For the complete FT $(2-10 \mathrm{~km})$, we found a mean mixing ratio of $0.56 \mathrm{ppt}$ with an atmospheric variability of $\pm 28 \%$. The measurements in the altitude range marked with Box B also show an enhanced mean mixing ratio $(0.62 \mathrm{ppt})$ and an enhanced atmospheric variability $( \pm 37 \%)$ with respect to the FT. This indicates that convective outflow detraining in the upper part of the FT can influence $\mathrm{CHBr}_{3}$ while this is not significant for the longerlived $\mathrm{CH}_{2} \mathrm{Br}_{2}$ which shows a much smaller vertical gradient.

The mixing ratios of $\mathrm{CHBr}_{3}$ in the FT are almost entirely below the value marked with the red dotted line in Fig. 4. As already suspected for $\mathrm{CH}_{2} \mathrm{Br}_{2}$, the air masses with the 


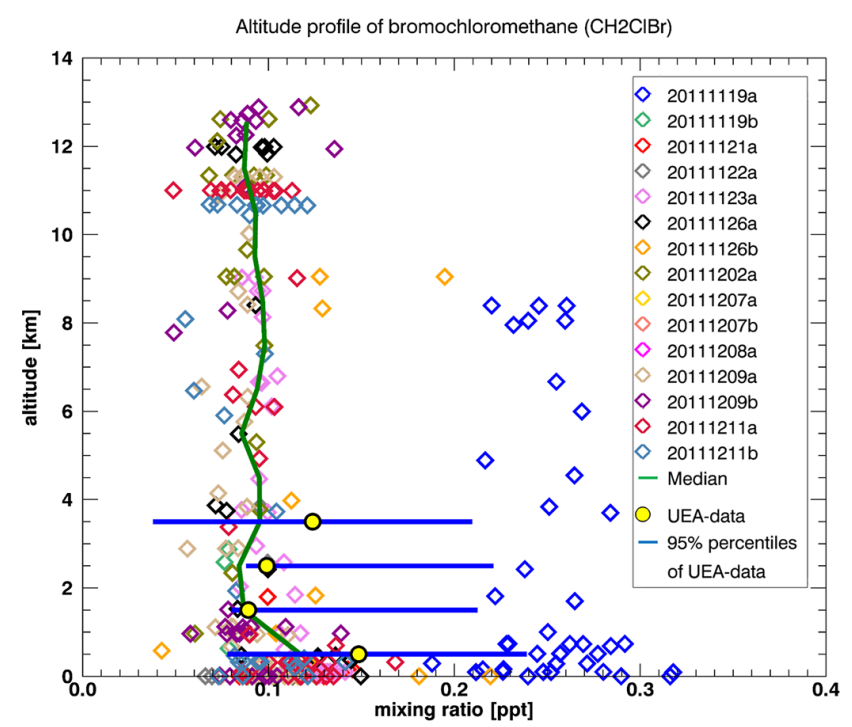

Figure 5. As Fig. 3, for $\mathrm{CH}_{2} \mathrm{BrCl}$.

high mixing ratios (Boxes A and B) must originate from atmospheric regions with higher mixing ratios. These are the regions below $2 \mathrm{~km}$, shown by Box C in Fig. 4 .

\subsection{Minor VSLS: $\mathrm{CH}_{2} \mathrm{BrCl}, \mathrm{CHBr}_{2} \mathrm{Cl}$ and $\mathrm{CHBrCl}_{2}$}

The altitude profile of $\mathrm{CH}_{2} \mathrm{BrCl}$ (shown in Fig. 5) shows a rather compact distribution with the exception of the observations from flight 20111119a. During this flight, very high mixing ratios were measured by the GHOST-MS instrument. These exceptional values are a factor of 2.5 higher than the mixing ratios measured during the rest of the campaign, but the simultaneous samples of the WASP instrument do not corroborate these GHOST-MS observations. Therefore, it cannot be excluded that this was a measurement error of the GHOST instrument, even though we have no indication of a malfunction during that particular flight.

Several studies (e.g. Brinckmann et al., 2012) reveal a poor correlation between $\mathrm{CH}_{2} \mathrm{BrCl}$ and the other brominated VSLS. This indicates that the sources of $\mathrm{CH}_{2} \mathrm{BrCl}$ differ significantly from those of the other VSLS. Therefore, a possible explanation might be that this flight was performed closer to a singular source of $\mathrm{CH}_{2} \mathrm{BrCl}$ than any other flight. However, enhanced mixing ratios for other VSLS $\left(\mathrm{CH}_{2} \mathrm{Br}_{2}\right.$ and $\mathrm{CHBrCl}_{2}$ ) were also observed on this flight. As these enhanced mixing ratios seemed not to be typical in this part of the western Pacific, the data from flight 20111119a are not included in the calculation of the tropical background distribution.

With a typical local lifetime of 137 days (Montzka and Reimann et al., 2011) in the lower troposphere, $\mathrm{CH}_{2} \mathrm{BrCl}$ has the longest lifetime of all brominated VSLS. With a mean mixing ratio in the PBL of $0.11 \mathrm{ppt}$ for GHOST and $0.15 \mathrm{ppt}$ for WASP, decreasing by $18 \%$ down to $0.09 \mathrm{ppt}$ in the UT,

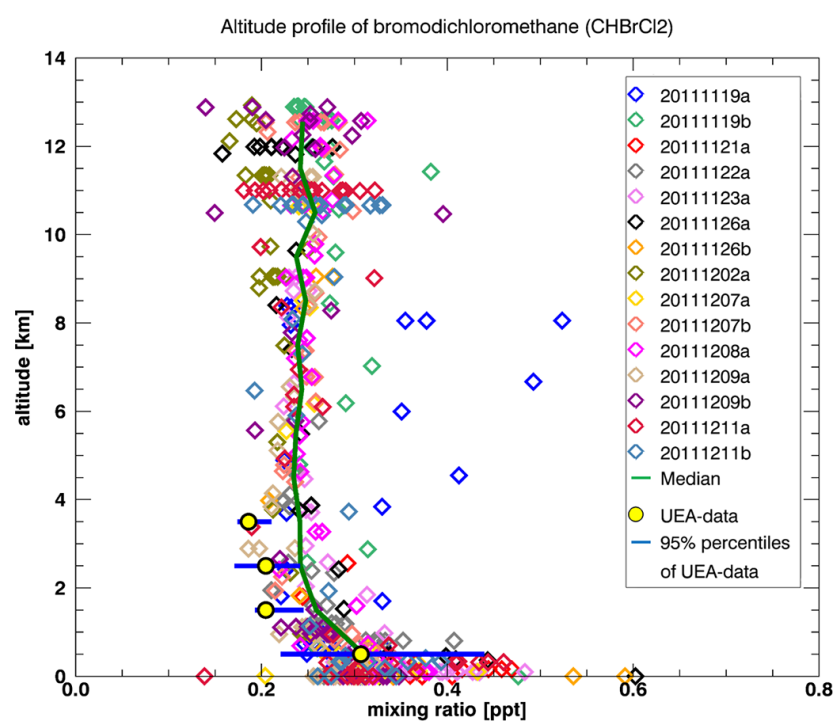

Figure 6. As Fig. 3, for $\mathrm{CHBrCl}_{2}$.

$\mathrm{CH}_{2} \mathrm{BrCl}$ is also the substance with the lowest mixing ratio of all brominated VSLS. Given the relative large uncertainties in the calibration for both data sets, $15 \%$ (GUF) and $9 \%$ (UEA) (see also Tables 2 and 3), the mean values given in Table 4 as well as the median in Fig. 5 match. However, the WASP data set from UEA seems to have a slightly higher variability in the PBL and the lower FT.

The relatively small decrease between the PBL and the free and upper troposphere can be explained by the relatively long lifetime, which leads to a rather homogeneous distribution of $\mathrm{CH}_{2} \mathrm{BrCl}$ in the observed altitudes. Another explanation for the low and rather homogeneous mixing ratios in the boundary layer could be that the measurements - except for flight 20111119a - have not probed air masses close to the source regions of $\mathrm{CH}_{2} \mathrm{BrCl}$. The atmospheric variability in the PBL is $\pm 21 \%$ for the GHOST and $33 \%$ for the WASP data set, $\pm 8 \%$ in the FT and $\pm 15 \%$ in the UT (only GHOST data). The vertical distribution and the atmospheric variability in the three compartments are comparable to those of $\mathrm{CH}_{2} \mathrm{Br}_{2}$, in agreement with the very similar lifetimes of both species.

The mean mixing ratio of $\mathrm{CHBrCl}_{2}$, which has a free tropospheric lifetime of 78 days (Montzka and Reimann et al., 2011), shows a decrease with altitude from $0.34 \mathrm{ppt}$ in the PBL to $0.24 \mathrm{ppt}$ in the UT, which corresponds to a decrease of $26 \%$. The atmospheric variability is $\pm 20 \%$ and $\pm 16 \%$, respectively, in the FT and UT, which is slightly larger than the variability of the longer-lived species $\mathrm{CH}_{2} \mathrm{Br}_{2}$ and $\mathrm{CH}_{2} \mathrm{BrCl}$ but smaller than for the two shorter-lived species $\mathrm{CHBr}_{2} \mathrm{Cl}$ and $\mathrm{CHBr}_{3}$.

As for $\mathrm{CH}_{2} \mathrm{Br}_{2}$, the agreement is excellent between the $\mathrm{CHBrCl}_{2}$ observations in the PBL from UEA and GUF as can be seen in Fig. 6 and Table 4. This is partly related to the fact that the mixing ratios of $\mathrm{CHBrCl}_{2}$ for GHOST rely on 
Table 5. Overview over the mean mixing ratios of the long-lived halons and $\mathrm{CH}_{3} \mathrm{Br}$ in the upper troposphere and the PBL as observed during SHIVA. The scatter is the absolute standard deviation of all measurements around the given mean value. The atmospheric variability is calculated as given in Eq. (3). For H-1301, no meaningful variability can be calculated (noted by n/a), as the scatter of the atmospheric measurements is smaller than the measurement precision of the instrument during the flight (see Sect. 2.2). Lifetimes for the halons are adapted from Newland et al. (2013) and the lifetime of $\mathrm{CH}_{3} \mathrm{Br}$ is taken from Montzka and Reimann et al. (2011).

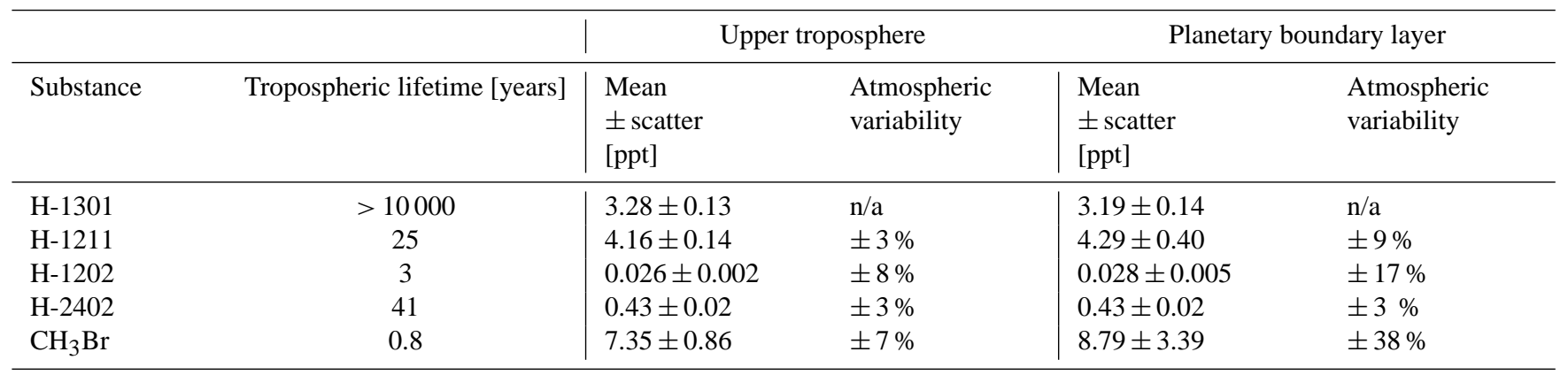

its linear relation with $\mathrm{CH}_{2} \mathrm{Br}_{2}$ (see Eq. 1) derived from the UEA observations during SHIVA, as both species cannot be chromatographically separated by the GHOST instrument.

$\mathrm{CHBr}_{2} \mathrm{Cl}$, whose altitude profile is shown in Fig. 7, has a typical lifetime of 59 days (Montzka and Reimann et al., 2011) in the FT. The mean mixing ratios in the PBL are $0.32 \mathrm{ppt}$ for GHOST, and $0.33 \mathrm{ppt}$ for WASP data. The decrease in the mixing ratio of $41 \%$ between the PBL and the UT, as well as the atmospheric variability with $\pm 34 \%$ (PBL) and $\pm 21 \%$ (UT) is already quite pronounced. The mixing ratio in the UT is the second lowest of all species discussed here. Regarding the effect of $\mathrm{CHBr}_{2} \mathrm{Cl}$ on stratospheric ozone depletion, this substance has nearly the same impact as the sum of the two longer-lived minor VSLS $\mathrm{CHBrCl}_{2}$ and $\mathrm{CH}_{2} \mathrm{BrCl}$. This is due to the fact that $\mathrm{CHBr}_{2} \mathrm{Cl}$ carries two bromine atoms while the other two minor VSLS carry only one.

\subsection{Long lived bromine source gases: halons and $\mathrm{CH}_{3} \mathrm{Br}$}

Due to their long atmospheric lifetimes and lack of sources, it would be expected that the mixing ratios of the halons are very homogeneous in the troposphere and no vertical gradient between the PBL and the UT is expected in the absence of significant tropospheric sinks. This is the case for $\mathrm{H}$ 1301 which has a tropospheric lifetime of more than 10000 years (Newland et al., 2013). H-1211 and H-2402 have small photolytic sinks in the troposphere with lifetimes of 25 and 41 years respectively (Newland et al., 2013). H-1202 is the only halon with a comparatively low tropospheric lifetime of about 3 years (Newland et al., 2013) and thus has a significant sink in the troposphere due to photolysis. The observed vertical distributions of the four halons are shown in Fig. 8; the corresponding mixing ratios are listed in Table 5.

The mean mixing ratio for $\mathrm{H}-1301$ (see Fig. 8a) is $3.19 \mathrm{ppt}$ in the PBL and $3.28 \mathrm{ppt}$ in the UT. For H-1301, the standard deviation of the atmospheric measurements is less than the measurement precision shown in Table 2. Consequently, no

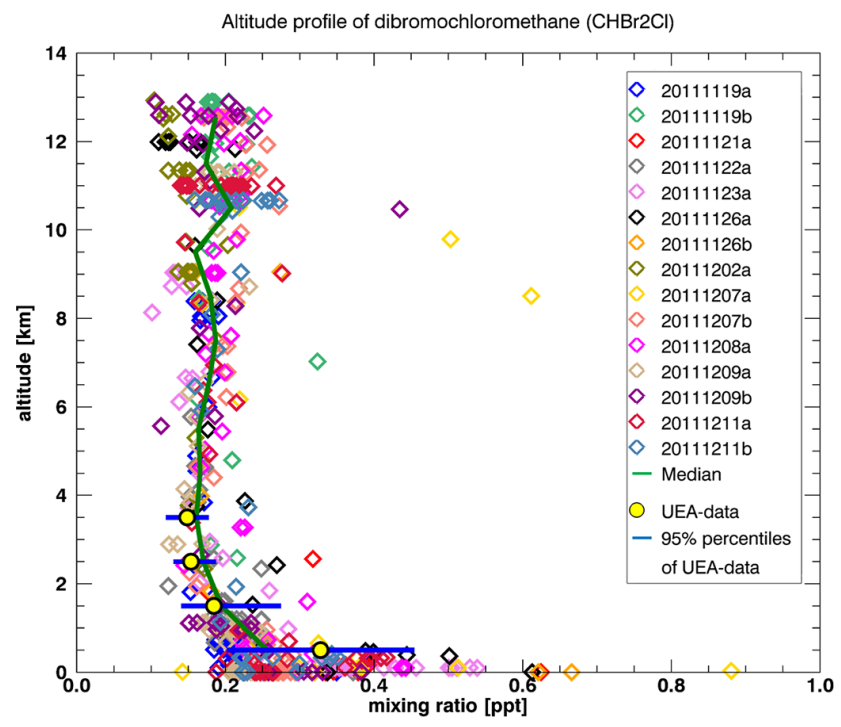

Figure 7. As Fig. 3, for $\mathrm{CHBr}_{2} \mathrm{Cl}$.

physically reasonable atmospheric variability can be calculated, because the value in the radicand in Eq. (3) becomes negative. It can therefore be assumed that the measured atmospheric variability is obscured by the measurement precision of the instrument. We note that while $\mathrm{H}-1301$ is also widely used as a fire extinguishing agent onboard passenger aircraft in fixed installations, no enhancement of this compound was observed at any of the rather small airports used for the refuelling stops. The difference between the PBL and the UT values is not significant within our uncertainties.

In the UT, H-1211 (see Fig. 8b) has a mean mixing ratio of $4.16 \mathrm{ppt}$ with an atmospheric variability of $\pm 3 \%$. The mean mixing ratio in the PBL is $4.29 \mathrm{ppt}$ with an atmospheric variability of $\pm 9 \%$. Some of the measurements conducted at ground show significantly higher values than the mean. The highest mixing ratio measured at the ground level is $6.88 \mathrm{ppt}$ of H-1211. All observations of significantly 

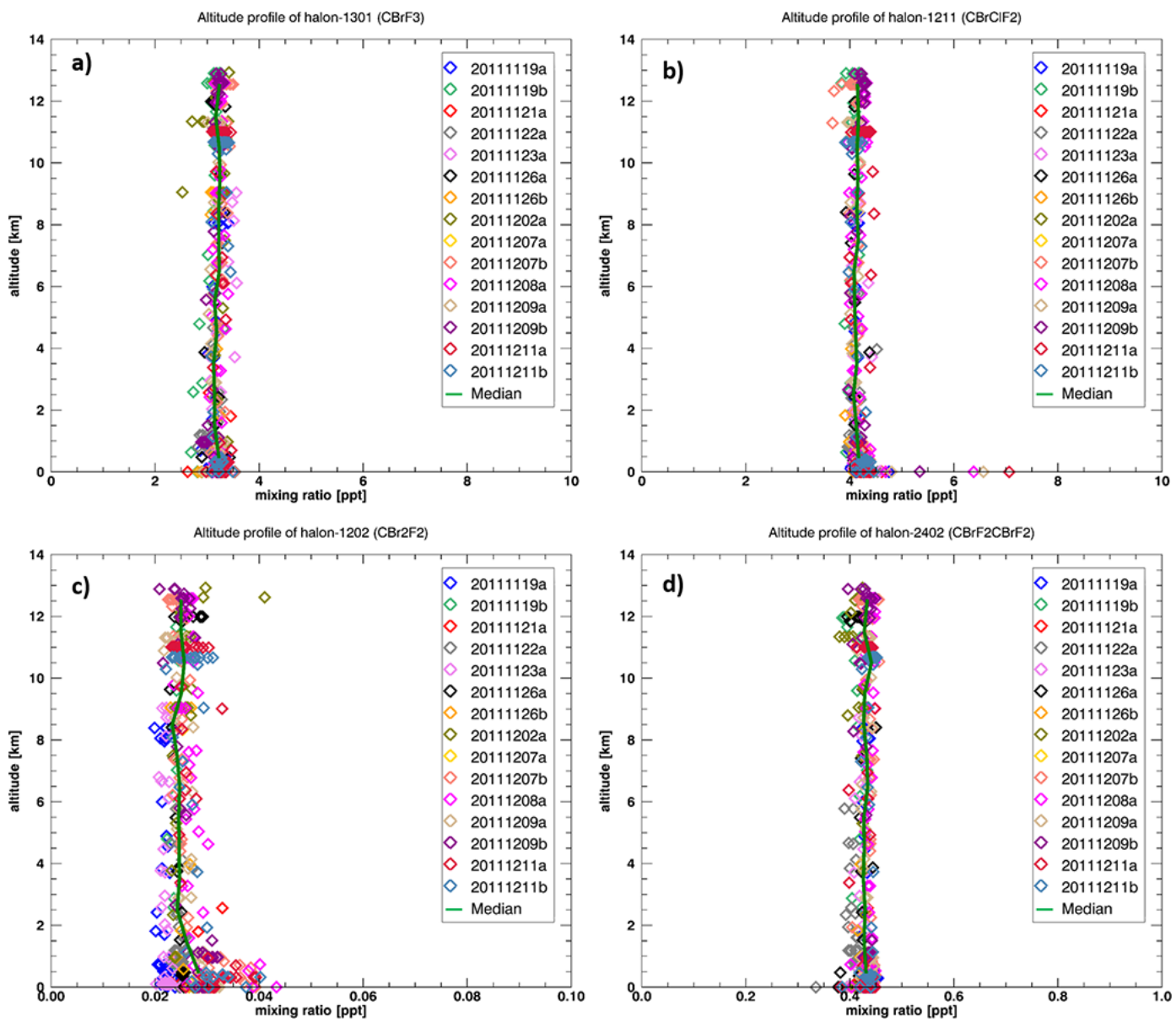

Figure 8. As Fig. 3, for H-1301 (a), H-1211 (b), H-1202 (c) and H-2402 (d).

enhanced H-1211 were made during refuelling stops at airports in Malaysia (e.g. Tawau). During the refuelling process on the runway the measurements were continued. H1211 was mainly used as a fire suppressant in portable fire extinguishers in aircraft (see e.g. HTOC, 2011). It is possible, that small leakages in those fire extinguishers lead to the enhanced mixing ratios observed at the airports.

H-2402 (see Fig. 8d) has an overall mean atmospheric mixing ratio of $0.43 \mathrm{ppt}$, with no observable difference between the PBL and the UT. The atmospheric variability $( \pm 3 \%)$ is also quite low. As this compound is used nearly exclusively in the states of the former Soviet Union (Newland et al., 2013) and the observations in Malaysia are far from the source region, no direct sources are expected even at airports.

H-1202 (see Fig. 8c) is the substance with the most pronounced atmospheric variability of all halons. With a mean mixing ratio of $0.028 \mathrm{ppt}$ in the PBL, the variability is $\pm 17 \%$. In the UT, the mean mixing ratio decreases down to $0.026 \mathrm{ppt}$, still showing an atmospheric variability of $\pm 8 \%$. This behaviour is expected compared to the other halons as H-1202 is the shortest lived of the four compounds.
The rather short tropospheric lifetime of about 3 years appears to be insufficient to lead to a significant vertical gradient but it is reflected in an enhanced variability with respect to the other halons.

$\mathrm{CH}_{3} \mathrm{Br}$ is the most abundant brominated substance in the atmosphere with a tropospheric lifetime of 0.8 years (Montzka and Reimann et al., 2011). The altitude profile of the measurements is shown in Fig. 9. The mixing ratios in the different altitude intervals are listed in Table 5. A mean mixing ratio of $8.79 \mathrm{ppt}$ in the PBL was observed with an atmospheric variability of $\pm 38 \%$. Within the PBL, some very high mixing ratios (up to $28.8 \mathrm{ppt}$ ) have been observed. These high values, as well as the pronounced variability, can be explained by the measurements being made close to sources of $\mathrm{CH}_{3} \mathrm{Br}$. In the UT, the mean mixing ratio decreases by $16 \%$ to $7.35 \mathrm{ppt}$, the atmospheric variability being $\pm 7 \%$, which is significantly lower than in the PBL. 


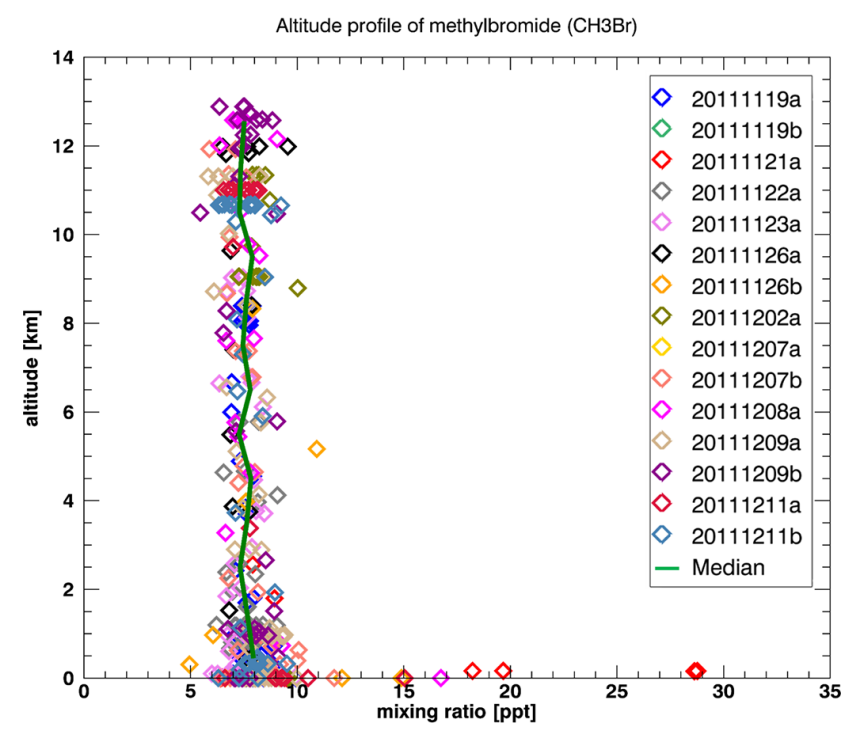

Figure 9. As Fig. 3, for $\mathrm{CH}_{3} \mathrm{Br}$.

\subsection{Comparison of the data set with data given in WMO 2010}

In this section we compare the data set obtained during SHIVA with the tropical VSLS data compiled in the last WMO report (Montzka and Reimann et al., 2011). Furthermore, we derive a budget of the total organic bromine in the upper troposphere over the western Pacific region from our measurements.

\subsubsection{Measurements in the boundary layer}

Available measurements of VSLS from the marine boundary layer up to the tropical tropopause are summarized in Montzka and Reimann et al. (2011), divided into six different altitude intervals. These data were obtained from different campaigns, as mentioned in Sect. 2. We compare our measurements with the data given for the marine boundary layer (listed in Table 6) and the upper troposphere (listed in Table 7). Note the slightly different definitions for the altitude intervals as explained in Sect. 2.4. Measurements from the ground up to $1000 \mathrm{~m}$ are summarized as marine boundary layer in Montzka and Reimann et al. (2011), whereas the marine boundary layer was found to be on average between 0 and $450 \mathrm{~m}$ during SHIVA.

For the comparison with the boundary layer values, the median instead of the arithmetic mean is used to ensure data comparability between the SHIVA and Montzka and Reimann et al. (2011) data sets.

The median values shown in Table 6 for the different VSLS in the boundary layer tend to be somewhat lower during the SHIVA campaign than the published values in Montzka and Reimann et al. (2011). Within the $1 \sigma$ measurement uncertainty the median value of $\mathrm{CH}_{2} \mathrm{Br}_{2}, \mathrm{CHBrCl}_{2}$ and $\mathrm{CHBr}_{2} \mathrm{Cl}$ for both instruments agrees with the median given in Montzka and Reimann et al. (2011). Assuming twice the measurement uncertainty, an agreement is also found for $\mathrm{CHBr}_{3}$. The values given for the TransBrom campaign are slightly lower than the measurements during SHIVA. This is due to the fact that the TransBrom measurements include more data from the open ocean than from coastal regions.

A very large discrepancy is observed for $\mathrm{CH}_{2} \mathrm{BrCl}$ between values of both instrument during SHIVA and the values reported by WMO. Even the ranges observed with the GHOST and WASP instruments during SHIVA and the range given in Montzka and Reimann et al. (2011) do not overlap. This discrepancy may be due to the fact that $\mathrm{CH}_{2} \mathrm{BrCl}$ is not correlated with the other VSLS and therefore entirely different sources could have been seen during the different campaigns without affecting the remaining VSLS. The boundary layer value for $\mathrm{CH}_{2} \mathrm{BrCl}$ in Montzka and Reimann et al. (2011) is directly transferred from (WMO, 2007). It is much higher than the free tropospheric and upper tropospheric values given in Montzka and Reimann et al. (2011). This may be an indication that this value is based on a calibration scale which is not compatible with the measurements reported here. Overall, the observed data ranges in the PBL for all five brominated VSLS during SHIVA are smaller than the ranges reported in Montzka and Reimann et al. (2011). However, the ranges given in Montzka and Reimann et al. (2011) are calculated in a slightly different way, as they are based on observations from different campaigns, regions and seasons, making this comparison difficult.

\subsubsection{Measurements in the upper troposphere}

In Montzka and Reimann et al. (2011) the interval between 10 and $12 \mathrm{~km}$ is defined as the upper troposphere. During SHIVA, the aircraft operated at a maximum altitude of $13 \mathrm{~km}$. As we see no further decay in mixing ratio of all organic brominated compounds between $12 \mathrm{~km}$ and $13 \mathrm{~km}$ during SHIVA, we use the range of 10 to $13 \mathrm{~km}$ for the upper troposphere in order to obtain better statistics. Observations in the same region have recently been published by Wisher et al. (2014).

Our observations in the upper troposphere during SHIVA, the data for SE Asia $\left(0-15^{\circ} \mathrm{N}\right)$ published in Wisher et al. (2014) and the data given by Montzka and Reimann et al. (2011) are summarized in Table 7. The data from Wisher et al. (2014) show a very good agreement with our measurements presented here for all VSLS.

Comparing our measurements with the data given in Montzka and Reimann et al. (2011), they agree within the $1 \sigma$ measurement uncertainty, with the exception of $\mathrm{CHBr}_{2} \mathrm{Cl}$ and $\mathrm{CHBrCl}_{2}$. In particular the values of $\mathrm{CHBrCl}_{2}$ presented in this work are about a factor of 2 higher than the WMO data. However, for both substances the range of the observations is in very good agreement with the values 
Table 6. Comparison of the boundary layer measurements during SHIVA derived independently from GHOST (GUF) and WASP (UEA) instrument with data compiled in Montzka and Reimann et al. (2011) and data from the TransBrom ship campaign (Brinckmann et al., 2012). The measurement uncertainty $(1 \sigma)$ of the SHIVA data is the sum of scale accuracy and instrumental measurement precision, excluding atmospheric variability. The range for the SHIVA data represents the 2.5 to 97.5 percentiles of the observed distribution.

\begin{tabular}{|c|c|c|c|c|c|c|c|c|}
\hline \multirow[b]{4}{*}{ Substance } & \multicolumn{2}{|c|}{ WMO (2010) } & \multicolumn{2}{|c|}{ TransBrom (2009) } & \multicolumn{4}{|c|}{ SHIVA (2011) } \\
\hline & \multicolumn{2}{|c|}{ Marine boundary layer } & \multicolumn{2}{|c|}{ Marine boundary layer } & \multicolumn{4}{|c|}{ Planetary boundary layer } \\
\hline & & & & & \multicolumn{2}{|c|}{ GHOST } & \multicolumn{2}{|c|}{ WASP } \\
\hline & $\begin{array}{l}\text { Median } \\
\text { [ppt] }\end{array}$ & $\begin{array}{l}\text { Range } \\
\text { [ppt] }\end{array}$ & $\begin{array}{l}\text { Mean } \\
{[\mathrm{ppt}]}\end{array}$ & $\begin{array}{l}\text { Range } \\
\text { [ppt] }\end{array}$ & $\begin{array}{l}\text { Median } \pm \\
\text { uncertainty } \\
\text { [ppt] }\end{array}$ & $\begin{array}{l}\text { Range } \\
\text { [ppt] }\end{array}$ & $\begin{array}{l}\text { Median } \pm \\
\text { uncertainty } \\
\text { [ppt] }\end{array}$ & $\begin{array}{l}\text { Range } \\
\text { [ppt] }\end{array}$ \\
\hline $\mathrm{CH}_{2} \mathrm{BrCl}$ & 0.5 & $0.4-0.6$ & 0.10 & $0.07-0.13$ & $0.11 \pm 0.02$ & $0.07-0.29$ & $0.12 \pm 0.01$ & $0.10-0.26$ \\
\hline $\mathrm{CH}_{2} \mathrm{Br}_{2}$ & 1.1 & $0.7-1.5$ & 0.92 & $0.69-1.21$ & $1.14 \pm 0.21$ & $0.94-1.62$ & $1.10 \pm 0.06$ & $0.96-1.48$ \\
\hline $\mathrm{CHBrCl}_{2}$ & 0.3 & $0.1-0.9$ & 0.20 & $0.16-0.30$ & $0.33 \pm 0.05$ & $0.26-0.48$ & $0.32 \pm 0.02$ & $0.23-0.52$ \\
\hline $\mathrm{CHBr}_{2} \mathrm{Cl}$ & 0.3 & $0.1-0.8$ & 0.14 & $0.09-0.34$ & $0.28 \pm 0.11$ & $0.20-0.62$ & $0.32 \pm 0.02$ & $0.22-0.59$ \\
\hline $\mathrm{CHBr}_{3}$ & 1.6 & $0.5-2.4$ & 0.91 & $0.44-2.16$ & $1.24 \pm 0.22$ & $0.60-2.54$ & $1.81 \pm 0.10$ & $1.23-3.35$ \\
\hline
\end{tabular}

Table 7. Comparison of the upper troposphere measurements during SHIVA from GHOST with data compiled in Montzka and Reimann et al. (2011) and data published in Wisher et al. (2013) from Southeast Asia $\left(0-15^{\circ} \mathrm{N}\right)$, derived from CARIBIC measurements. The measurement uncertainty $(1 \sigma)$ given for the SHIVA data is the sum of scale accuracy and instrumental measurement precision, excluding atmospheric variability. The range for the SHIVA data represents the 2.5 to 97.5 percentiles of the observed distribution.

\begin{tabular}{|c|c|c|c|c|c|c|}
\hline \multirow[b]{2}{*}{ Substance } & \multicolumn{2}{|c|}{$\begin{array}{c}\text { WMO, } 2010 \text { upper } \\
\text { troposphere }(10-12 \mathrm{~km})\end{array}$} & \multicolumn{2}{|c|}{$\begin{array}{l}\text { SHIVA, } 2011 \text { upper } \\
\text { troposphere }(10-13 \mathrm{~km})\end{array}$} & \multicolumn{2}{|c|}{$\begin{array}{l}\text { CARIBIC, 2012/2013 upper } \\
\text { troposphere }(>10 \mathrm{~km})\end{array}$} \\
\hline & $\begin{array}{l}\text { Mean } \\
{[\mathrm{ppt}]}\end{array}$ & $\begin{array}{l}\text { Range } \\
\text { [ppt] }\end{array}$ & $\begin{array}{l}\text { Mean } \pm \\
\text { uncertainty } \\
\text { [ppt] }\end{array}$ & $\begin{array}{l}\text { Range } \\
\text { [ppt] }\end{array}$ & $\begin{array}{l}\text { Mean } \pm \\
\text { uncertainty } \\
\text { [ppt] }\end{array}$ & $\begin{array}{l}\text { Full range } \\
{[\mathrm{ppt}]}\end{array}$ \\
\hline $\mathrm{CH}_{2} \mathrm{BrCl}$ & 0.09 & $0.03-0.16$ & $0.09 \pm 0.02$ & $0.06-0.26$ & $0.12 \pm 0.01$ & $0.09-0.14$ \\
\hline $\mathrm{CH}_{2} \mathrm{Br}_{2}$ & 0.86 & $0.63-1.21$ & $0.90 \pm 0.12$ & $0.71-1.22$ & $0.92 \pm 0.08$ & $0.74-1.00$ \\
\hline $\mathrm{CHBrCl}_{2}$ & 0.11 & $0.02-0.28$ & $0.25 \pm 0.04$ & $0.19-0.35$ & $0.21 \pm 0.03$ & $0.16-0.31$ \\
\hline $\mathrm{CHBr}_{2} \mathrm{Cl}$ & 0.11 & $0.01-0.36$ & $0.19 \pm 0.04$ & $0.12-0.27$ & $0.16 \pm 0.02$ & $0.08-0.19$ \\
\hline $\mathrm{CHBr}_{3}$ & 0.50 & $0.12-1.21$ & $0.61 \pm 0.11$ & $0.28-1.01$ & $0.56 \pm 0.12$ & $0.15-0.81$ \\
\hline
\end{tabular}

of $(0.23 \pm 0.13)$ ppt for $\mathrm{CHBrCl}_{2}$ and $(0.15 \pm 0.08) \mathrm{ppt}$ for $\mathrm{CHBr}_{2} \mathrm{Cl}$ reported by Wisher et al. (2014) derived from CARIBIC air samples. The discrepancy for these two minor VSLS given in Montzka and Reimann et al. (2011) is not well understood. It might be due to calibration uncertainties as well as due to natural variability in the different sampling regions and seasons.

The ratio between the values measured in the upper troposphere and the boundary layer, which is the source region for the TTL, is a measure of the chemical decay between both reservoirs. This ratio is shown in Table 8 for the values compiled in Montzka and Reimann et al. (2011) and our observations during SHIVA. In general, it is expected that the decay is stronger for shorter-lived compounds. Overall, the observed gradient in the mixing ratios of the VSLS between the two altitude intervals is weaker during SHIVA. The greatest discrepancy between the two data sets is found for $\mathrm{CH}_{2} \mathrm{BrCl}$. The decline of this substance given by Montzka and Reimann et al. (2011) is more than four times larger than that derived
Table 8. Comparison of the decay of the VSLS between boundary layer and upper troposphere $(10-13 \mathrm{~km})$. The lifetime is given for the free troposphere (Montzka and Reimann et al., 2011).

\begin{tabular}{llll}
\hline Substance & $\begin{array}{l}\text { Free tropospheric } \\
\text { lifetime [days] }\end{array}$ & Decay WMO & Decay SHIVA \\
\hline $\mathrm{CH}_{2} \mathrm{BrCl}$ & 137 & $-82 \%$ & $-18 \%$ \\
$\mathrm{CH}_{2} \mathrm{Br}_{2}$ & 123 & $-22 \%$ & $-24 \%$ \\
$\mathrm{CHBrCl}_{2}$ & 78 & $-63 \%$ & $-26 \%$ \\
$\mathrm{CHBr}_{2} \mathrm{Cl}$ & 59 & $-63 \%$ & $-41 \%$ \\
$\mathrm{CHBr}_{3}$ & 24 & $-69 \%$ & $-51 \%$ \\
\hline
\end{tabular}

from the SHIVA observations. A decay of the same order as observed for $\mathrm{CH}_{2} \mathrm{Br}_{2}$ and a significantly smaller decay than that observed for the shorter-lived $\mathrm{CHBr}_{3}$ would be expected for $\mathrm{CH}_{2} \mathrm{BrCl}$ due to its lifetime. Two other substances presented in Montzka and Reimann et al. (2011), $\mathrm{CHBrCl}_{2}$ and 
Table 9. Overview of long-lived brominated substances. The global tropospheric mean for $\mathrm{H}-1301, \mathrm{H}-1211, \mathrm{H}-2402$ and $\mathrm{CH}{ }_{3} \mathrm{Br}$ are an update of Montzka et al. (2003), H-1202 is taken from Newland et al. (2013). The measurement uncertainty is the sum of scale accuracy and instrumental measurement precision. The atmospheric variability is not contained in the value.

\begin{tabular}{lcc}
\hline Substance & $\begin{array}{c}\text { Global tropospheric background } \\
(\text { late } 2011)\end{array}$ & $\begin{array}{c}\text { SHIVA, free and upper troposphere } \\
(2-13 \mathrm{~km})(\text { mean } \pm \text { uncertainty })\end{array}$ \\
\hline $\mathrm{H}-1301$ & $3.19 \mathrm{ppt}$ & $(3.23 \pm 0.21) \mathrm{ppt}$ \\
$\mathrm{H}-1211$ & $3.97 \mathrm{ppt}$ & $(4.15 \pm 0.10) \mathrm{ppt}$ \\
$\mathrm{H}-2402$ & $0.45 \mathrm{ppt}$ & $(0.43 \pm 0.02) \mathrm{ppt}$ \\
$\mathrm{H}-1202$ & $0.020 \mathrm{ppt}$ & $(0.025 \pm 0.002) \mathrm{ppt}$ \\
$\mathrm{CH}_{3} \mathrm{Br}$ & $6.96 \mathrm{ppt}$ & $(7.50 \pm 0.64) \mathrm{ppt}$ \\
\hline
\end{tabular}

$\mathrm{CHBr}_{2} \mathrm{Cl}$, also feature a surprisingly strong negative vertical gradient.

The best estimate of the typical free tropospheric lifetime of the VSLS is in the range from 137 days $\left(\mathrm{CH}_{2} \mathrm{BrCl}\right)$ to 24 days $\left(\mathrm{CHBr}_{3}\right)$. Due to this rather narrow range of tropospheric lifetimes the different substances should display rather similar decay rates. In the SHIVA data set, the decay is in the range of $20-30 \%$ for all VSLS except for the two shortest-lived species, $\mathrm{CHBr}_{2} \mathrm{Cl}$ and $\mathrm{CHBr}_{3}$. This may be due to the different chemical degradation processes. Both species have significant photochemical loss and in the case of $\mathrm{CHBr}_{3}$ photolysis, which is mostly independent of altitude, is the dominant loss process. Chemical degradation via the $\mathrm{OH}$ radical is dominant for the other VSLS. However, the rate constants for the reaction with the $\mathrm{OH}$ radical show a strong temperature dependence (Hossaini et al., 2010; Orkin et al., 2013) and this loss process is thus much less efficient at higher altitudes due to decreasing temperature. The decay rates based on the data compiled in Montzka and Reimann et al. (2011) show a much more inhomogeneous pattern. In particular, no relationship between the decay between PBL and UT and the lifetime is observed for the data compiled in Montzka and Reimann et al. (2011), whilst our observations clearly show that for the VSLS the vertical gradient between both reservoirs is anticorrelated to their lifetime.

These large differences in the degradation rates for the WMO data are most probably caused by inconsistent calibration scales and the combination of observations from different regions and periods. In particular, for the mixed bromochlorocarbons $\mathrm{CH}_{2} \mathrm{BrCl}, \mathrm{CHBrCl}_{2}$ and $\mathrm{CHBr}_{2} \mathrm{Cl}$ no consistent and internationally intercompared calibration scales yet exist. This is so far only available to a certain degree for $\mathrm{CH}_{2} \mathrm{Br}_{2}$ and $\mathrm{CHBr}_{3}$ (Hall et al., 2014; Jones et al., 2011). In contrast the SHIVA data derived from GUF with the GHOST instrument presented here rely on the same calibration gas scale for the different altitude regions and are from one period and region. This emphasizes the need for a consistent calibration scale for VSLS species and for vertically resolved observations from different regions and during different seasons.
Table 9 shows the mixing ratios of the long-lived halons and $\mathrm{CH}_{3} \mathrm{Br}$ obtained during SHIVA and compared with calculated tropospheric mean values at the end of 2011. The global tropospheric mean values are derived from different ground-based measurements at remote locations from the NOAA-ESRL network (Montzka et al., 2003). For the comparison, we use our data from the free and upper troposphere, since it can be assumed that these air masses are not influenced by local sources from the boundary layer. In addition, the changes in mixing ratio between the boundary layer and the free troposphere are insignificant for these long-lived substances compared to the VSLS. Therefore, the long-lived substances are not significantly affected by convective transport from the boundary layer in the free and upper troposphere.

The mixing ratios for the long-lived substances show an overall very good agreement with the H-1301, H-1211, H2402 and $\mathrm{CH}_{3} \mathrm{Br}$ data published by Montzka et al. (2003), (updated) and the $\mathrm{H}-1202$ data published by Newland et al. (2013). H-1211 and H-1202 show slightly higher mixing ratios during SHIVA, but they still agree within the $2 \sigma$ uncertainty. For the remaining three substances we find a match within the $1 \sigma$ measurement uncertainty. With the exception of H-2402, all long-lived substances measured during SHIVA show a slightly enhanced mixing ratio in comparison with the global tropospheric background. This may be due to the fact that occasionally slightly polluted air was sampled during the SHIVA campaign and therefore even the measurements in the free and upper troposphere do not reflect completely remote air masses. This is consistent with the vertical profiles presented in Figs. 3 and 4, showing that convection can locally transport boundary layer air to the free and upper troposphere. Another circumstance which has to be taken into account is the link of our calibration gas scale to the NOAA Scale. In the International Halocarbons in Air Experiment (IHALACE) (Hall et al., 2014), which was carried out from 2004 to 2006, our laboratory reported slightly higher mixing ratios for $\mathrm{H}-1301$ and $\mathrm{H}-1211$ compared to the NOAA laboratory. 
Table 10. Comparison of the total organic bromine in the upper troposphere between SHIVA and the global average in 2011. The data given for the global average of H-1301, H-1211, H-2402 and $\mathrm{CH}_{3} \mathrm{Br}$ are an update of Montzka et al. (2003), H-1202 is taken from Newland et al. (2013) and the VSLS data are from Montzka and Reimann et al. (2011). For the calculation of the total organic bromine, the mean mixing ratio (given in Tables 7 and 9) of an individual source gas is multiplied by its number of bromine atoms. The measurement uncertainty is the sum of scale accuracy and instrumental measurement precision.

\begin{tabular}{lcccc}
\hline \multirow{2}{*}{ Substance class } & \multicolumn{2}{c}{ Global average, year 2011 } & \multicolumn{2}{c}{ SHIVA, year 2011 } \\
\cline { 2 - 5 } & $\mathrm{Br}_{\text {org }}[\mathrm{ppt}]$ & Percentage of total $\mathrm{Br}_{\text {org }}$ & $\mathrm{Br}_{\text {org }}$ 士 measurement uncertainty [ppt] & Percentage of total Br $\mathrm{Brg}$ \\
\hline Halons & 8.10 & $43.3 \%$ & $8.31 \pm 0.58$ & $(41.5 \pm 3.0) \%$ \\
$\mathrm{CH}_{3} \mathrm{Br}$ & 6.96 & $37.2 \%$ & $7.35 \pm 0.60$ & $(36.7 \pm 3.0) \%$ \\
$\mathrm{VSLS}$ & 3.64 & $19.5 \%$ & $4.35 \pm 0.44$ & $(21.8 \pm 3.0) \%$ \\
$\Sigma \mathrm{Br}_{\text {org }}$ & 18.70 & $100 \%$ & $20.01 \pm 1.62$ & $100 \%$ \\
\hline
\end{tabular}

\section{Budget of total organic bromine in the upper troposphere}

Table 10 shows a comparison of the total organic bromine budget for the upper troposphere derived from GHOST measurements during SHIVA and "WMO data" reported in Montzka and Reimann et al. (2011). The budget of total organic bromine calculated from the SHIVA data (20.01 ppt $\pm 1.62 \mathrm{ppt})$ is slightly higher $(7 \%)$ than that derived in Montzka and Reimann et al. (2011) for the total organic bromine (18.70ppt), although consistent within the uncertainties. The SHIVA results for the five VSLS are also in very good agreement with airborne observations presented in Wisher et al. (2014) for the same region. The combined halons show an elevated mixing ratio $(8.31 \mathrm{ppt} \pm 0.58 \mathrm{ppt})$ by $2.6 \%$ in the SHIVA data set, whilst the mixing ratios for $\mathrm{CH}_{3} \mathrm{Br}(7.35 \mathrm{ppt} \pm 0.60 \mathrm{ppt})$ and the combined VSLS are elevated by $5.6 \%$ and $20 \%$, respectively. The contribution of the VSLS to total organic bromine from the SHIVA data set is $(4.35 \pm 0.44) \mathrm{ppt}$ for the upper troposphere. This is $0.71 \mathrm{ppt}$ or $20 \%$ higher than the value for the tropical troposphere as a whole given in Montzka and Reimann et al. (2011), and therefore slightly outside our estimated uncertainty range, supporting the finding that the western Pacific may be a slightly stronger source region for VSLS (Wisher et al., 2014).

With respect to the individual substance classes, the halons contribute most $(41.5 \%$ SHIVA, $43.3 \% \mathrm{WMO})$ to the total organic bromine, with $\mathrm{CH}_{3} \mathrm{Br}$ making a slightly smaller contribution ( $36.7 \%$ SHIVA, $37.2 \%$ WMO). The smallest contribution to the total organic bromine in the upper troposphere is from VSLS (21.8\% SHIVA, $19.5 \%$ WMO). In general, the overall agreement between the total organic bromine found during SHIVA and reported by Montzka and Reimann et al. (2011) is still in the range of the $1 \sigma$ uncertainty. The percentage partitioning by the three substance classes is nearly the same in the two data sets. The altitude profile of total organic bromine is shown in Fig. 10.

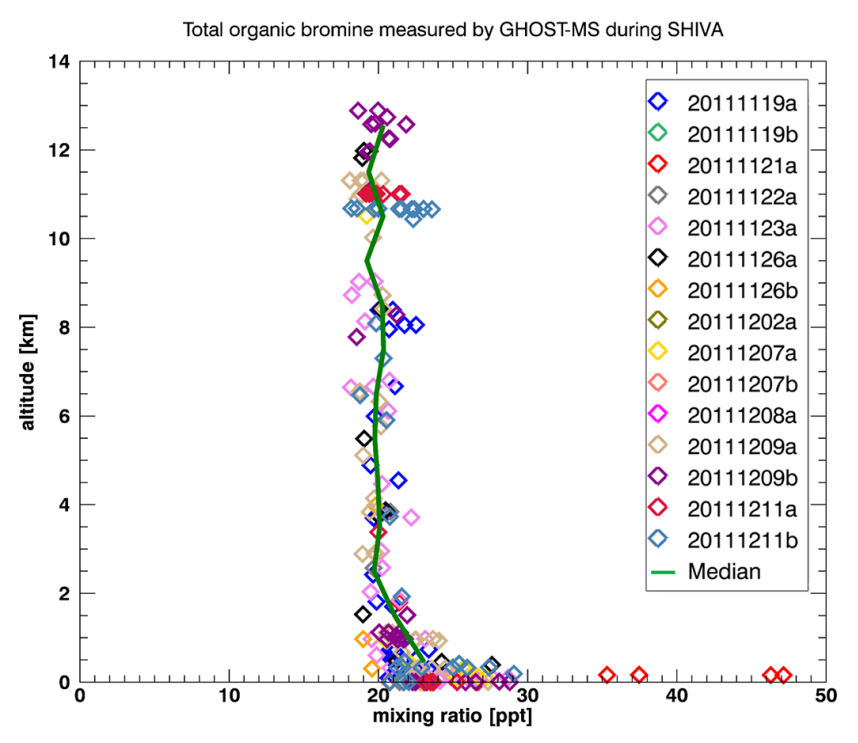

Figure 10. As Fig. 3, for total organic bromine. Only samples with mixing ratio data for all 10 bromocarbons are shown.

\section{Budget of total organic bromine at the LZRH}

In order to obtain information about the quantity of total organic bromine entering the stratosphere, we consider the budget at the level of zero radiative heating (LZRH), in a similar way as suggested in Montzka and Reimann et al. (2011). Air masses reaching this level are expected to enter the stratosphere. Under this condition, it is assumed that product gases released from source gases above this level are also transported into the stratosphere. According to Gettelman et al. (2004) the LZRH is located between $15 \mathrm{~km}$ and $15.6 \mathrm{~km}$, an altitude which could not be reached during SHIVA. The maximum altitude reached during the SHIVA campaign was about $13 \mathrm{~km}$. To obtain information about the mixing ratios of the substances and therefore a bromine budget at the LZRH, we make the following assumptions: (i) for the longlived halons and $\mathrm{CH}_{3} \mathrm{Br}$ we assume that there is no change in the mixing ratio between the UT and the LZRH, and (ii) for the shorter-lived VSLS, we assume that the degradation 
Table 11. Mean mixing ratios of the VSLS in the upper troposphere and the LZRH. The decay shows the decrease in mixing ratio between the upper troposphere and the LZRH given in Montzka and Reimann et al. (2011), denoted as WMO. With these decay rates, the expected mixing ratios for the LZRH during SHIVA are calculated. The mixing ratio of $\mathrm{CH}_{2} \mathrm{BrCl}$ is kept constant, as there is no physical indication of an increase as given in the WMO data.

\begin{tabular}{|c|c|c|c|c|c|}
\hline \multirow[b]{2}{*}{ Substance } & \multicolumn{3}{|c|}{ Mean mixing ratio $\mathrm{WMO}[\mathrm{ppt}]$} & \multicolumn{2}{|c|}{ Mean mixing ratio SHIVA [ppt] } \\
\hline & Upper troposphere & LZRH & Decay & Upper troposphere & LZRH, calculated \\
\hline $\mathrm{CH}_{2} \mathrm{BrCl}$ & 0.09 & 0.10 & $(+11 \%)$ & 0.09 & 0.09 \\
\hline $\mathrm{CH}_{2} \mathrm{Br}_{2}$ & 0.86 & 0.74 & $-14 \%$ & 0.90 & 0.77 \\
\hline $\mathrm{CHBrCl}_{2}$ & 0.11 & 0.10 & $-9 \%$ & 0.25 & 0.23 \\
\hline $\mathrm{CHBr}_{2} \mathrm{Cl}$ & 0.11 & 0.06 & $-45 \%$ & 0.19 & 0.10 \\
\hline $\mathrm{CHBr}_{3}$ & 0.50 & 0.22 & $-56 \%$ & 0.61 & 0.27 \\
\hline
\end{tabular}

Table 12. Budget of total organic bromine at the LZRH with the contribution of different substance classes. The VSLS value for the SHIVA campaign is calculated from the estimate described in Table 11 using the decay in mixing ratio between UT and LZRH. The values given for SHIVA are (mean mixing ratio \pm measurement uncertainty). The measurement uncertainty is the sum of scale accuracy and instrumental measurement precision. The global average values (see also Tables 7 and 9) are from Montzka et al. (2003) ${ }^{1}$ (updated) and Newland et al. $(2013)^{2}$ (for H-1202), and Montzka and Reimann et al. (2011) ${ }^{3}$. The values given for Teresina are from Brinckmann et al. (2012) ${ }^{4}$ and Laube et al. (2008). Low VSLS values $\left(^{*}\right)$ found in Teresina (2005) are most probably due to sample loss in the canisters caused by the long period which elapsed between sampling and analysis of the air samples.

\begin{tabular}{lcccc}
\hline Substance class & SHIVA, Malaysia 2011 (calculated) & Global average 2011 & Teresina, Brazil 2008 & Teresina, Brazil 2005 \\
\hline Halons & $(8.31 \pm 0.58) \mathrm{ppt}$ & $8.10 \mathrm{ppt}^{1,2}$ & $8.17 \mathrm{ppt}$ & $8.29 \mathrm{ppt}$ \\
$\mathrm{CH}_{3} \mathrm{Br}$ & $(7.35 \pm 0.60) \mathrm{ppt}$ & $6.96 \mathrm{ppt}^{1}$ & $7.40 \mathrm{ppt}$ & $6.68 \mathrm{ppt}$ \\
$\mathrm{VSLS}$ & $(2.88 \pm 0.29) \mathrm{ppt}$ & $2.70 \mathrm{ppt}^{3}$ & $2.25 \mathrm{ppt}$ & $1.25 \mathrm{ppt}^{*}$ \\
$\Sigma_{\mathbf{B r}}$ & $(18.54 \pm 1.47) \mathrm{ppt}$ & $17.76 \mathrm{ppt}$ & $(17.82 \pm 0.66) \mathrm{ppt}$ & $(16.22 \pm 1.10) \mathrm{ppt}$ \\
\hline
\end{tabular}

between these two altitude levels derived from the data presented in Montzka and Reimann et al. (2011) is applicable to our observations as well. We therefore compare the values given for the individual substances in Montzka and Reimann et al. (2011) for the UT and the LZRH (Table 1-7 in Montzka and Reimann et al., 2011) and calculate a percental degradation rate. With these assumptions, we can use our measurements in the UT to estimate values for the LZRH during the SHIVA campaign. The results for these calculations are shown in Table 11.

The values for $\mathrm{CH}_{2} \mathrm{BrCl}$ given in Montzka and Reimann et al. (2011) for the different altitude intervals originate from different campaigns. This may explain the - physically not very meaningful - increase in mixing ratio by $11 \%$ between the UT and the $\mathrm{LZRH}$. The mixing ratio of $\mathrm{CH}_{2} \mathrm{BrCl}$ is therefore assumed to be constant between these two levels for the SHIVA data set. For the remaining VSLS a decline between the UT and the LZRH is observed in the data compiled in Montzka and Reimann et al. (2011), which is most pronounced for $\mathrm{CHBr}_{3}$ with a value of $56 \%$.

In analogy to the bromine budget for the UT presented in Sect. 3.6, we calculate a budget of the total organic bromine at the LZRH using the calculated values given in Table 11. The results of this LZRH bromine budget are presented in Table 12 and compared with previously published data. We calculate a contribution of $(2.88 \pm 0.29)$ ppt from VSLS at the
LZRH to total organic bromine. Within the degree of measurement uncertainty, this value agrees with the VSLS data (2.70 ppt) given in Montzka and Reimann et al. (2011). Furthermore, the overall amount of total organic bromine calculated for the SHIVA campaign (18.54 \pm 1.47$)$ ppt agrees with the total bromine calculation $(17.76 \mathrm{ppt})$ given in Montzka and Reimann et al. (2011).

The SHIVA data set can also be compared with the results from two measurement campaigns using balloon-borne whole-air samplers, which were carried out by the Goethe University Frankfurt (GUF). These two campaigns were carried out in 2005 (Laube et al., 2008) and 2008 (Brinckmann et al., 2012) in Teresina, Brazil $\left(5^{\circ} \mathrm{S}\right)$. Using a cryogenic whole-air sampler (e.g. Engel et al., 1997), samples at an altitude of $15.20 \mathrm{~km}$ (year 2005) and $14.85 \mathrm{~km}$ (year 2008) were collected during these campaigns and analysed afterwards using a GC / MS system in the laboratory in Frankfurt. The analysis for a wide range of halocarbons was done half a year (2005) and two months (2008) after the samples were taken. For the long-lived substances very good agreement was seen between the mixing ratios calculated from SHIVA and those observed during the Teresina campaigns. For the combined VSLS, Brinckmann et al. (2012) found a lower value $(2.25 \mathrm{ppt})$ at the LZRH, although this is still in agreement within its measurement uncertainty with the value of $(2.88 \pm 0.29)$ ppt calculated from the SHIVA data. The mix- 
ing ratio of combined VSLS at the LZRH found by Laube et al. (2008) is substantially lower (1.25 ppt) than that expected by other studies and our calculations. This low mixing ratio is most probably due to the long period which elapsed between sampling and analysis of the air samples. As shown by Laube (2008) and verified by Brinckmann (2011), a decomposition of short-lived substances can occur in the stainless steel sampling canisters. The decrease cannot be quantified, as it is - among other things - a function of water vapour content, sample pressure and the surface conditions of the individual sample canister. These things are highly variable and therefore difficult to characterize. Another contributing factor may be the slightly higher sampling altitude (and therefore longer transport time of the air mass into this region) of the measurement from the year 2005 .

\section{Conclusions}

During the SHIVA aircraft campaign in Malaysia, which took place in November and December 2011, more than 500 samples of ambient air were measured with an in situ GC/MS and about 215 whole air samples were collected and analysed post-flight with a similar GC/MS system. In total 16 scientific flights have been performed in the boundary layer as well as in the free and upper troposphere. From these air samples, mixing ratios of four long-lived halons, methyl bromide and five very short-lived substances, including the two major VSLS dibromomethane and bromoform, have been determined.

The independent observations of VSLS derived from the two instruments show very good agreement within the $2 \sigma$ measurement uncertainty over the whole overlapping vertical range of both instruments (see Figs. 2-5 and Tables 4 and 6).

The atmospheric variability in the different altitude intervals increases with decreasing lifetime of a VSLS. The shorter the lifetime of a VSLS the stronger is the decrease in mixing ratio between PBL and FT and between PBL and UT respectively. This leads to a very pronounced altitude profile for the shortest lived VSLS with the highest mixing rations of VSLS observed in the boundary layer.

The calculated value for the total organic bromine in the upper troposphere is $(20.01 \pm 1.62)$ ppt including $(4.35 \pm 0.44) \mathrm{ppt}$ derived from VSLS. Both values are slightly higher than those reported by Montzka and Reimann et al. (2011), but only the latter is slightly outside the range of the $1 \sigma$ uncertainty.

With respect to the entry of bromine in the stratosphere, the estimation of the bromine content at the LZRH gives a value of $(18.54 \pm 1.47) \mathrm{ppt}$ and a contribution of $(2.88 \pm 0.29) \mathrm{ppt}$ from VSLS, reflecting a fraction of $16 \%$ of the total bromine budget. The amount of total organic bromine from VSLS at the LZRH is only $0.18 \mathrm{ppt}$ higher than the value for the tropical troposphere as a whole calculated by Montzka and Reimann et al. (2011), whilst be- ing slightly higher than previous estimates from GUF based on balloon-borne measurements over Teresina/Brazil (Laube et al., 2008; Brinckmann et al., 2012). The difference between the VSLS mixing ratios observed during SHIVA and the conspicuously low values observed during the Teresina 2005 campaign are most likely caused by the long storage of the balloon canisters before the analysis (Laube et al., 2008).

Generally, a good agreement is found for the comparison of the data obtained during SHIVA with those published in Montzka and Reimann et al. (2011), which are mainly from measurement campaigns in the central and eastern Pacific. The main exceptions to this good agreement are $\mathrm{CH}_{2} \mathrm{BrCl}$ in the boundary layer, where we find much lower values, and $\mathrm{CHBrCl}_{2}$ as well as $\mathrm{CHBr}_{2} \mathrm{Cl}$ in the upper troposphere, where we find somewhat higher mixing ratios. Slightly higher mixing ratios of short-lived bromine species in the upper troposphere of the western Pacific have also recently been suggested by Wisher et al. (2014) in comparison with aircraft measurements over Central America and Africa. As noted, for example, by Ashfold et al. (2012) natural variability such as the phase of the ENSO and seasonality may affect the sources and sinks of VSLS and their transport into the upper troposphere. Altogether, this shows that the western Pacific may be a preferred region for VSLS transport to the stratosphere. However, the total organic bromine and the total number of VSLS at the LZRH calculated from the SHIVA data set give only a weak indication of enhanced source gas injection of organic bromine into the stratosphere in this region. More vertically resolved observations are crucially needed to sample the entire range of natural variability and to confirm this possible role of the western Pacific as a source region for stratospheric halogens from short-lived species.

Acknowledgements. This work was supported by the EU project SHIVA under grant number 226224 and by DFG (projects FACT and GHOST-MS, EN 367/5-1 and EN367/5-2). The contribution of Laurin Hermann to the development of GHOST-MS is gratefully acknowledged. GUF also thanks enviscope $\mathrm{GmbH}$ for excellent cooperation during the aircraft certification of GHOST-MS. We thank the coordinators Klaus Pfeilsticker and Marcel Dorf as well as the DLR flight department and Andreas Dörnbrack (meteorological support) for their excellent support during the campaign. Thanks to Klaus Pfeilsticker for providing the overview table of the campaign and thanks to Anja Reiter for the corresponding map with the flight tracks of the Falcon.

Edited by: J. Williams 


\section{References}

Apel, E. C., Hills, A. J., Lueb, R., Zindel, S., Eisele, S., and Riemer, D. D.: A fast-GC/MS system to measure C-2 to C-4 carbonyls and methanol aboard aircraft, J. Geophys. Res.-Atmos., 108, 8794, doi:10.1029/2002jd003199, 2003.

Aschmann, J., Sinnhuber, B.-M., Atlas, E. L., and Schauffler, S. M.: Modeling the transport of very short-lived substances into the tropical upper troposphere and lower stratosphere, Atmos. Chem. Phys., 9, 9237-9247, doi:10.5194/acp-9-9237-2009, 2009.

Ashfold, M. J., Harris, N. R. P., Atlas, E. L., Manning, A. J., and Pyle, J. A.: Transport of short-lived species into the Tropical Tropopause Layer, Atmos. Chem. Phys., 12, 6309-6322, doi:10.5194/acp-12-6309-2012, 2012.

Baker, J. M., Sturges, W. T., Sugier, J., Sunnenberg, G., Lovett, A. A., Reeves, C. E., Nightingale, P. D., and Penkett, S. A.: Emissions of $\mathrm{CH} 3 \mathrm{Br}$, organochlorines, and organoiodines from temperate macroalgae, Chemosphere - Global Change Sci., 3, 93106, doi:10.1016/S1465-9972(00)00021-0, 2001.

Brinckmann, S.: Short-lived brominated Hydrocarbons: Observations in the Source-Regions and in the Stratosphere, $\mathrm{PhD}$ Thesis, Goethe University Frankfurt, 2011.

Brinckmann, S., Engel, A., Boenisch, H., Quack, B., and Atlas, E.: Short-lived brominated hydrocarbons - observations in the source regions and the tropical tropopause layer, Atmos. Chem. Phys., 12, 1213-1228, doi:10.5194/acp-12-1213-2012, 2012.

Carpenter, L. J., and Liss, P. S.: On temperate sources of bromoform and other reactive organic bromine gases, J. Geophys. Res. Atmos., 105, 20539-20547, doi:10.1029/2000JD900242, 2000.

Carpenter, L. J., Liss, P. S., and Penkett, S. A.: Marine organohalogens in the atmosphere over the Atlantic and Southern Oceans, J. Geophys. Res.-Atmos., 108, 4256, doi:10.1029/2002JD002769, 2003

Carpenter, L. J., Fleming, Z. L., Read, K. A., Lee, J. D., Moller, S. J., Hopkins, J. R., Purvis, R. M., Lewis, A. C., Mueller, K., Heinold, B., Herrmann, H., Fomba, K. W., van Pinxteren, D., Mueller, C., Tegen, I., Wiedensohler, A., Mueller, T., Niedermeier, N., Achterberg, E. P., Patey, M. D., Kozlova, E. A., Heimann, M., Heard, D. E., Plane, J. M. C., Mahajan, A., Oetjen, H., Ingham, T., Stone, D., Whalley, L. K., Evans, M. J., Pilling, M. J., Leigh, R. J., Monks, P. S., Karunaharan, A., Vaughan, S., Arnold, S. R., Tschritter, J., Poehler, D., Friess, U., Holla, R., Mendes, L. M., Lopez, H., Faria, B., Manning, A. J., and Wallace, D. W. R.: Seasonal characteristics of tropical marine boundary layer air measured at the Cape Verde Atmospheric Observatory, J. Atmos. Chem., 67, 87-140, doi:10.1007/s10874-011-9206-1, 2010.

Dorf, M., Butler, J. H., Butz, A., Camy-Peyret, C., Chipperfield, M. P., Kritten, L., Montzka, S. A., Simmes, B., Weidner, F., and Pfeilsticker, K.: Long-term observations of stratospheric bromine reveal slow down in growth, Geophys. Res. Lett., 33, L24803, doi:10.1029/2006g1027714, 2006.

Engel, A., Schmidt, U., and Stachnik, R. A.: Partitioning between chlorine reservoir species deduced from observations in the arctic winter stratosphere, J. Atmos. Chem., 27, 107-126, 1997.

Fraser, P. J., Oram, D. E., Reeves, C. E., Penkett, S. A., and McCulloch, A.: Southern Hemispheric halon trends (1978-1998) and global halon emissions, J. Geophys. Res., 104, 15985-15999, doi:10.1029/1999JD900113, 1999.

Fueglistaler, S., Wernli, H., and Peter, T.: Tropical troposphereto-stratosphere transport inferred from trajectory cal- culations, J. Geophys. Res.-Atmos., 109, D03180, doi:10.1029/2003JD004069, 2004.

Fueglistaler, S., Dessler, A. E., Dunkerton, T. J., Folkins, I., Fu, Q., and Mote, P. W.: Tropical tropopause layer, Rev. Geophys., 47, RG1004, doi:10.1029/2008rg000267, 2009.

Fuhlbrügge, S., Krüger, K., Quack, B., Atlas, E., Hepach, H., and Ziska, F.: Impact of the marine atmospheric boundary layer conditions on VSLS abundances in the eastern tropical and subtropical North Atlantic Ocean, Atmos. Chem. Phys., 13, 6345-6357, doi:10.5194/acp-13-6345-2013, 2013.

Gettelman, A. and Forster, P. M. D.: A climatology of the tropical tropopause layer, Journal of the Meteorological Society of Japan, 80, 911-924, doi:10.2151/jmsj.80.911, 2002.

Gettelman, A., Salby, M. L., and Sassi, F.: Distribution and influence of convection in the tropical tropopause region, J. Geophys. Res.-Atmos., 107, doi:10.1029/2001jd001048, 2002.

Gettelman, A., Forster, P. M. D., Fujiwara, M., Fu, Q., Vomel, H., Gohar, L. K., Johanson, C., and Ammerman, M.: Radiation balance of the tropical tropopause layer, J. Geophys. Res.-Atmos., 109, D07103, doi:10.1029/2003JD004190, 2004

Hall, B. D., Engel, A., Mühle, J., Elkins, J. W., Artuso, F., Atlas, E., Aydin, M., Blake, D., Brunke, E.-G., Chiavarini, S., Fraser, P. J., Happell, J., Krummel, P. B., Levin, I., Loewenstein, M., Maione, M., Montzka, S. A., O'Doherty, S., Reimann, S., Rhoderick, G., Saltzman, E. S., Scheel, H. E., Steele, L. P., Vollmer, M. K., Weiss, R. F., Worthy, D., and Yokouchi, Y.: Results from the International Halocarbons in Air Comparison Experiment (IHALACE), Atmos. Meas. Tech., 7, 469-490, doi:10.5194/amt-7469-2014, 2014.

Hossaini, R., Chipperfield, M. P., Monge-Sanz, B. M., Richards, N. A. D., Atlas, E., and Blake, D. R.: Bromoform and dibromomethane in the tropics: a 3-D model study of chemistry and transport, Atmos. Chem. Phys., 10, 719-735, doi:10.5194/acp10-719-2010, 2010.

Hossaini, R., Mantle, H., Chipperfield, M. P., Montzka, S. A., Hamer, P., Ziska, F., Quack, B., Krüger, K., Tegtmeier, S., Atlas, E., Sala, S., Engel, A., Bönisch, H., Keber, T., Oram, D., Mills, G., Ordóñez, C., Saiz-Lopez, A., Warwick, N., Liang, Q., Feng, W., Moore, F., Miller, B. R., Marécal, V., Richards, N. A. D., Dorf, M., and Pfeilsticker, K.: Evaluating global emission inventories of biogenic bromocarbons, Atmos. Chem. Phys., 13, 11869-11886, doi:10.5194/acp-13-11869-2013, 2013.

HTOC: Assessment Report of the Halon Technical Options Committee 2010, Ozone Secretariat, UNEP, Nairobi, Kenya, 2011.

Jones, C. E., Andrews, S. J., Carpenter, L. J., Hogan, C., Hopkins, F. E., Laube, J. C., Robinson, A. D., Spain, T. G., Archer, S. D., Harris, N. R. P., Nightingale, P. D., O’Doherty, S. J., Oram, D. E., Pyle, J. A., Butler, J. H., and Hall, B. D.: Results from the first national UK inter-laboratory calibration for very short-lived halocarbons, Atmos. Meas. Tech., 4, 865-874, doi:10.5194/amt4-865-2011, 2011.

Kley, D., Crutzen, P. J., Smit, H. G. J., Vomel, H., Oltmans, S. J., Grassl, H., and Ramanathan, V.: Observations of near-zero ozone concentrations over the convective Pacific: Effects on air chemistry, Science, 274, 230-233, doi:10.1126/science.274.5285.230, 1996.

Krüger, K. and Quack, B.: Introduction to special issue: the TransBrom Sonne expedition in the tropical West Pacific, Atmos. 
Chem. Phys., 13, 9439-9446, doi:10.5194/acp-13-9439-2013, 2013.

Laube, J. C.: Determination of the distribution of halocarbons in the tropical upper troposphere and stratosphere, $\mathrm{PhD}$ Thesis, Goethe University Frankfurt, 2008.

Laube, J. C., Engel, A., Bonisch, H., Mobius, T., Worton, D. R., Sturges, W. T., Grunow, K., and Schmidt, U.: Contribution of very short-lived organic substances to stratospheric chlorine and bromine in the tropics - a case study, Atmos. Chem. Phys., 8, 7325-7334, doi:10.5194/acp-8-7325-2008, 2008.

Law and Sturges, K., Blake, D. R., Blake, N. J., Burkholder, J. B., Butler, J. H., Cox, R. A., Haynes, P. H., Ko, M. K. W., Kreher, K., Mari, C., Pfeilsticker, K., Plane, J. M. C., Salawitch, R. J., Schiller, C., Sinnhuber, B.-M., von Glasow, R., Warwick, N. J., Wuebbles, D. J., and Yvon-Lewis, S. A.: Halogenated Very Short-Lived Substances, Chapter2 in Scientific Assessment of Ozone Depletion: 2006, Global Ozone Research and Monitoring Project - Report No.50, World Meteorological Organization, Geneva, Switzerland, 2007, 2007.

Leedham, E. C., Hughes, C., Keng, F. S. L., Phang, S. M., Malin, G., and Sturges, W. T.: Emission of atmospherically significant halocarbons by naturally occurring and farmed tropical macroalgae, Biogeosciences, 10, 3615-3633, doi:10.5194/bg-10-3615-2013, 2013.

Liang, Q., Stolarski, R. S., Kawa, S. R., Nielsen, J. E., Douglass, A. R., Rodriguez, J. M., Blake, D. R., Atlas, E. L., and Ott, L. E.: Finding the missing stratospheric $\mathrm{Br}_{\mathrm{y}}$ : a global modeling study of $\mathrm{CHBr}_{3}$ and $\mathrm{CH}_{2} \mathrm{Br}_{2}$, Atmos. Chem. Phys., 10, 2269-2286, doi:10.5194/bg-10-2269-2010, 2010.

Miller, B. R., Weiss, R. F., Salameh, P. K., Tanhua, T., Greally, B. R., Muhle, J., and Simmonds, P. G.: Medusa: A sample preconcentration and GC / MS detector system for in situ measurements of atmospheric trace halocarbons, hydrocarbons, and sulfur compounds, Anal. Chem., 80, 1536-1545, doi:10.1021/ac702084k, 2008.

Montzka and Reimann, Engel, A., Krüger, K., O’Doherty, S., Sturges, W. T., Blake, D., Dorf, M., Fraser, P., Froidevaux, L., Jucks, K., Kreher, K., Kurylo, M. J., Mellouki, A., Miller, J., Nielsen, O.-J., Orkin, V. L., Prinn, R. G., Rhew, R., Santee, M. L., and Verdonik, D.: Ozone-Depleting Substances (ODSs) and Related Chemicals, Chapter 1 in Scientific Assessment of Ozone Depletion: 2010, Global Ozone Research and Monitoring Project-Report No. 52, World Meteorological Organization, Geneva, Switzerland, 516 pp., 2011.

Montzka, S. A., Butler, J. H., Myers, R. C., Thompson, T. M., Swanson, T. H., Clarke, A. D., Lock, L. T., and Elkins, J. W.: Decline in the tropospheric abundance of halogen from halocarbons: Implications for stratospheric ozone depletion, Science, 272, 13181322, 1996.

Montzka, S. A., Butler, J. H., Hall, B. D., Mondeel, D. J., and Elkins, J. W.: A decline in tropospheric organic bromine, Geophys. Res. Lett., 30, 1826, doi:10.1029/2003GL017745, 2003.

Newell, R. E. and Gould-Stewart, S.: A stratospheric fountain, J. Atmos. Sci., 38, 2789-2796, doi:10.1175/15200469(1981)038<2789:ASF>2.0.CO;2, 1981.

Newland, M. J., Reeves, C. E., Oram, D. E., Laube, J. C., Sturges, W. T., Hogan, C., Begley, P., and Fraser, P. J.: Southern hemispheric halon trends and global halon emissions, 1978-2011,
Atmos. Chem. Phys., 13, 5551-5565, doi:10.5194/acp-13-55512013, 2013.

Oram, D. E., Reeves, C. E., Penkett, S. A., and Fraser, P. J.: Measurements of HCFC-142b and HCFCc-141b in the Cape-Grim Air Archive - 1978-1993, Geophys. Res. Lett., 22, 2741-2744, Doi 10.1029/95gl02849, 1995.

Orkin, V. L., Khamaganov, V. G., Kozlov, S. N., and Kurylo, M. J.: Measurements of Rate Constants for the OH Reactions with Bromoform (CHBr3), $\mathrm{CHBr} 2 \mathrm{Cl}, \mathrm{CHBrCl}_{2}$, and Epichlorohydrin (C3H5ClO), J. Phys. Chem. A, 117, 38093818, doi:10.1021/JP3128753, 2013.

Pyle, J. A., Ashfold, M. J., Harris, N. R. P., Robinson, A. D., Warwick, N. J., Carver, G. D., Gostlow, B., O’Brien, L. M., Manning, A. J., Phang, S. M., Yong, S. E., Leong, K. P., Ung, E. H., and Ong, S.: Bromoform in the tropical boundary layer of the Maritime Continent during OP3, Atmos. Chem. Phys., 11, 529-542, doi:10.5194/acp-11-529-2011, 2011.

Quack, B. and Wallace, D. W. R.: Air-sea flux of bromoform: Controls, rates, and implications (vol 17, art no 1023, 2003), Global Biogeochem. Cy., 18, GB1004, doi:10.1029/2003GB002187, 2004.

Rex, M., Wohltmann, I., Ridder, T., Lehmann, R., Rosenlof, K., Wennberg, P., Weisenstein, D., Notholt, J., Krüger, K., Mohr, V., and Tegtmeier, S.: A tropical West Pacific $\mathrm{OH}$ minimum and implications for stratospheric composition, Atmos. Chem. Phys., 14, 4827-4841, doi:10.5194/acp-14-4827-2014, 2014.

Roedel, W.: Die Atmosphäre, 4. Auflage, Springer-Verlag Berlin Heidelberg, 65-97, doi:10.1007/978-3-642-15729-5, 2011.

Sala, S.: Entwicklung und Einsatz eines flugzeuggetragenen GC / MS - Systems zum Nachweis halogenierter Kohlenwasserstoffe in der Atmosphäre, PhD Thesis, Goethe University Frankfurt, 2014.

Schauffler, S. M., Atlas, E. L., Donnelly, S. G., Andrews, A., Montzka, S. A., Elkins, J. W., Hurst, D. F., Romashkin, P. A., Dutton, G. S., and Stroud, V.: Chlorine budget and partitioning during the Stratospheric Aerosol and Gas Experiment (SAGE) III Ozone Loss and Validation Experiment (SOLVE), J. Geophys. Res.-Atmos., 108, 4173, doi:10.1029/2001jd002040, 2003.

Seibert, P., Beyrich, F., Gryning, S.-E., Joffre, S., Rasmussen, A., and Tercier, P.: Review and intercomparison of operational methods for the determination of the mixing height, Atmos. Environ., 34, 1001-1027, doi:10.1016/S1352-2310(99)00349-0, 2000.

Sinnhuber, B. M., Sheode, N., Sinnhuber, M., Chipperfield, M. P., and Feng, W.: The contribution of anthropogenic bromine emissions to past stratospheric ozone trends: a modelling study, Atmos. Chem. Phys., 9, 2863-2871, doi:10.5194/acp-9-2863-2009, 2009.

Solomon, S., Thompson, D. W. J., Portmann, R. W., Oltmans, S. J., and Thompson, A. M.: On the distribution and variability of ozone in the tropical upper troposphere: Implications for tropical deep convection and chemical-dynamical coupling, Geophys. Res. Lett., 32, L23813, doi:10.1029/2005GL024323, 2005.

Tegtmeier, S., Krüger, K., Quack, B., Atlas, E. L., Pisso, I., Stohl, A., and Yang, X.: Emission and transport of bromocarbons: from the West Pacific ocean into the stratosphere, Atmos. Chem. Phys., 12, 10633-10648, doi:10.5194/acp-1210633-2012, 2012.

Warwick, N. J., Pyle, J. A., Carver, G. D., Yang, X., Savage, N. H., O'Connor, F. M., and Cox, R. A.: Global model- 
ing of biogenic bromocarbons, J. Geophys. Res.-Atmos., 111, doi:10.1029/2006JD007264, 2006.

Wisher, A., Oram, D. E., Laube, J. C., Mills, G. P., van Velthoven, P., Zahn, A., and Brenninkmeijer, C. A. M.: Very short-lived bromomethanes measured by the CARIBIC observatory over the North Atlantic, Africa and Southeast Asia during 2009-2013, Atmos. Chem. Phys., 14, 3557-3570, doi:10.5194/acp-14-35572014, 2014.

WMO: Scientific Assessment of Ozone depletion, Global Ozone Research and Monitoring Project, World Meteorological Organization, Geneva, Switzerland, 2007.

Worton, D. R., Mills, G. P., Oram, D. E., and Sturges, W. T.: Gas chromatography negative ion chemical ionization mass spectrometry: Application to the detection of alkyl nitrates and halocarbons in the atmosphere, J. Chromatogr. A, 1201, 112-119, doi:10.1016/j.chroma.2008.06.019, 2008.
Yokouchi, Y., Hasebe, F., Fujiwara, M., Takashima, H., Shiotani, M., Nishi, N., Kanaya, Y., Hashimoto, S., Fraser, P., ToomSauntry, D., Mukai, H., and Nojiri, Y.: Correlations and emission ratios among bromoform, dibromochloromethane, and dibromomethane in the atmosphere, J. Geophys. Res.-Atmos., 110, D23309, doi:10.1029/2005JD006303, 2005.

Ziska, F., Quack, B., Abrahamsson, K., Archer, S. D., Atlas, E., Bell, T., Butler, J. H., Carpenter, L. J., Jones, C. E., Harris, N. R. P., Hepach, H., Heumann, K. G., Hughes, C., Kuss, J., Krueger, K., Liss, P., Moore, R. M., Orlikowska, A., Raimund, S., Reeves, C. E., Reifenhaeuser, W., Robinson, A. D., Schall, C., Tanhua, T., Tegtmeier, S., Turner, S., Wang, L., Wallace, D., Williams, J., Yamamoto, H., Yvon-Lewis, S., and Yokouchi, Y.: Global sea-toair flux climatology for bromoform, dibromomethane and methyl iodide, Atmos. Chem. Phys., 13, 8915-8934, doi:10.5194/acp13-8915-2013, 2013. 